Final 06022006

\title{
PUBLIC POLICY AND THE DEVELOPMENT OF A UK NATIONAL GEOGRAPHIC INFORMATION STRATEGY
}

\author{
Dr. STEPHEN SAXBY ${ }^{1}$
}

\begin{abstract}
In March 2005 the Government published a report ${ }^{2}$ assessing the progress that had been made since 1999 in embracing digital technology in the UK. It declared that there had been a transformation in its use within the UK economy and civil society and that Britain had moved dramatically up international league tables in the take-up of IT and in its engagement in the e-economy. Since the Millennium, the Government has been busy re-organising its procurement and service arrangements and information channels. It has encouraged departments and agencies to embrace digital technology and to capture the efficiency gains that this can offer. New offices have been established within the reporting structures of the Cabinet Office and HM Treasury to drive these initiatives forward. They are the e-Government Unit, the Office of Government Commerce and the Office of Public Sector Information. The Office of the Deputy Prime Minister is also active in the management of geographic information. A key driver for these Offices is engaging with digital technology in a form that will both advance the UK economy and improve business and consumer access to information and services. This paper explores these issues in the context of one specific area of policy viz., the creation, development and exploitation of geographic information within a spatial data infrastructure. The latter raises, in microcosm, many of the issues that the Government must tackle as it develops its digital and eGovernment transformation agendas. This paper will assess to what extent the Government can be said to have clear objectives as to how it plans to develop a geographic information strategy for the UK. It also considers what needs to be done to enable the diverse range of organisations, both within the public and private sectors, to move forward in the promotion of geographic information services as a supporting mechanism to the delivery of eGovernment policies.
\end{abstract}

\section{The Digital National Framework}

One of the most significant uses of digital technology has been observed in the exploitation of geospatial ('geographic') information (GI) i.e. "information that can be mapped, or communicates 'where' a person or object is located in relation to others." 3 The desire to develop interoperable tools to utilise the link between 'location' and 'geography' within information systems has grown significantly in the past five years, including at government level. ${ }^{4} \mathrm{GI}^{5}$ is described as a specialised

\footnotetext{
${ }^{1}$ Reader in Information Technology Law, Southampton University, PhD, Solicitor. My thanks to Keith Murray, Head of Geographic Information Strategy, Ordnance Survey and Phil Watts, Corporate Strategist (Long Term Strategy), Ordnance Survey for their very helpful analysis of an earlier draft of this paper.

${ }^{2}$ Connecting the UK: the Digital Strategy, (Cabinet Office, Prime Minister's Strategy Unit - A joint report with the Department of Trade and Industry, March 2005).

${ }^{3}$ Gary Nairn, Federal MP for Eden Monaro, NSW Australia at http://spatialinfocrc.org/pages/about.aspx.

${ }^{4}$ K. Murray, B. Munday \& I. Bush, Enabling Information Integrity within Spatial Data Infrastructures - The Digital National Framework Concept, From Pharaohs to Geoinformatics, FIG Working Week 2005 and GSDI-8 Cairo, Egypt April 16-21 2005.
} 
component of the IT sector with scientific and technical links to disciplines such as environmental science, engineering, computer science, health delivery, logistics, planning, resource management and electronics. ${ }^{6}$ Its practical applications are extraordinarily wide from policy making to social and commercial activity. It, therefore, has significant economic potential. A private sector GI industry has spawned.

In the UK Ordnance Survey (OS), as the UK's national mapping Agency, has contributed significantly to these developments. A mapmaker for government since the mid-eighteenth century, OS has steadily built its capability both in the UK and overseas. In November 2001, it launched OS MasterMap, "a detailed and definitive topographic framework for England, Wales and Scotland."7 This is based on the national grid reference system, ${ }^{8}$ proposed following a review by the Davidson Committee $^{9}$ in 1935 that was commissioned to consider the future of OS. OS MasterMap contains more than 420 million features of the landscape and contains layers of GI divided into themes of the built and natural environment such as land, buildings, highways/paths, and water etc. ${ }^{10}$ The four layers of OS MasterMap, introduced so far, are the Address Layer - giving precise co-ordinates to 26 million residential and commercial properties in Great Britain (GB); the Imagery Layer - a detailed aerial photographic map of GB 'orthorectified' to represent exactly what is on the ground; the Integrated Transport Network (ITN) Layer - a detailed overview of GB's transport infrastructure; and the Topography Layer - an underpinning database of the surface features of the landscape. ${ }^{11}$ Thus, a template is provided in the form of a layered database of geographic information to which reference ${ }^{12}$ or applications data ${ }^{13}$ may be added to produce a versatile GI tool. ${ }^{14}$ The user can attach an overlay of geospatial data to suit the particular application required. It was OS' intention to encourage the formation of explicit connections between objects defined on its maps so as to achieve clarity and interoperability with any other data that may be added to the template.

Prior to the launch of OS MasterMap difficulties existed in establishing automated GI analysis tools that could link and share applications with some forms of reference information without human interference. ${ }^{15}$ OS MasterMap set out to tackle this problem and grew from an initiative, first discussed in the 1980's but finally announced in 1999, to develop a Digital National Framework

\footnotetext{
${ }^{5}$ Defined as "information about objects or phenomena that are associated with a location relative to the surface of the earth - a special case of spatial information.” From Ordnance Survey Glossary: Mapping terminology and acronyms at: www.ordnancesurvey.co.uk.

${ }^{6}$ Ibid.

${ }^{7}$ K.J. Murray, G. Hart \& P. Allan, The Digital National Framework - Bridging Information through Geography at http://www.isprs.org/istanbul2004/comm4/papers/359.pdf.

${ }^{8}$ A metric grid based on the Tranverse Mercator Projection developed by Ordnance Survey in 1936 for use in Great Britain. Referred to in GIS by the code "OSGB36 ${ }^{\circledR}$ " it is the de facto standard projection for display of mapping in Great Britain.

${ }^{9}$ Ministry of Agriculture and Fisheries, Final Report of the Departmental Committee on the Ordnance Survey, Chair: Viscount Davidson (London, HMSO 1938 SO Code: 1938 24.142).

${ }^{10}$ K.J. Murray, “The Digital National Framework - underpinning the Knowledge Economy”, 2 Data Science Journal, October 2003, p.146 at 149.

${ }^{11}$ See further: /www.ordnancesurvey.co.uk/oswebsite/products/osmastermap/index.html. In the DNF model (see below) all other objects are referenced to the topographic features that represent real world objects.

${ }^{12}$ Reference data normally includes data or information that underpins or is used as a reference base for applications data. The type of reference data varies according to the provider e.g. local authority or water company.

${ }^{13}$ Applicatons data refers to the georeferencing of information to a location e.g. scene of a battle.

${ }^{14}$ Major detailed urban information is recorded in the database within 6 months and rural areas are updated every five years. Over one million additions, modifications or deletions take place each year. Source: op. cit., note 8 ante at p.150.

${ }^{15}$ Op.cit. note 6 ante, section 4.1 .
} 
(DNF). ${ }^{16}$ The concept of a DNF evolved "to support greater connectivity across all kinds of business information managed by separate organisations, where that information has 'location' as a common denominator." 17 Its aim was to provide a model for the "integration of geographic information of all kinds - from national datasets to application information at local level." ${ }^{18}$ In doing so the intent was to produce a permanent, maintained and definitive geographic base that could be secured and supported by a set of enabling principles and operational rules. These should "underpin and facilitate the integration of geo-referenced information from multiple sources."19 The key to the DNF, therefore, was the desire to adopt consistent approaches in the modelling of information, geo-referencing and data exchange. It is not "owned" by any one organisation and is intended to evolve to meet customer needs in a politically and commercially neutral environment.

The anchors linking user application information to location are the 440 million 'DNF compliant' topographic identifiers (TOIDs). ${ }^{20}$ These were allocated by OS, maintained in the National Topographic Database (NTD) and deployed in the Topography Layer of OS MasterMap. Providing a consistent form of geo-referencing is a major step forward for the DNF. This is beginning to produce a distributed network of joined up datasets. TOIDs are one example of unique identifiers that can be implemented within the DNF, leaving room for users to develop their own identifiers, linked to features within the common framework. This has been aided by the development of common standards, in particular those promoted by the Open Geospatial Consortium (OGC). ${ }^{21}$ These have the potential to build a global platform for growth of geographic information-based web services. $^{22}$ The DNF Expert Group has proposed the creation of a central DNF Registry to provide a searchable directory of all 'DNF-enabled' datasets. In its view this would enable the user "to identify particular information and, through distributed service providers, have it streamed into their network via web services." 23 The Expert Group argues that such a Registry could also offer a repository of technical documents, standards and guidelines concerning the DNF as well as promoting its principles but DNF does not intend to supply services other than documentation and the registry to support the standard.

\footnotetext{
${ }^{16}$ In fact various attempts had been made at this, the TDB trail in the late 80's, Project 93, OS96 - the lack of funding, unbalanced Business case defeated them all.
}

\footnotetext{
${ }^{17}$ The Digital National Framework - evolving a framework for interoperability across all kinds of information - A White Paper by Ordnance Survey (September 2004).

${ }^{18}$ Ibid., p.13.

19 Ibid.

${ }^{20}$ This is a unique 16 digit topographic identifier used for all points, lines and areas. It provides a common link that allows different data to reference the same feature and allows users to cross reference data in ways that are likely to add value to their data. Source: A. Trigg, The Digital National Framework of Great Britain at: http://www.gsdidocs.org/gsdiconf/GSDI-6/Streeam3/Wednesday_14hr/Andrew_Trigg/atrigg_GSDI_paper.pdf. Only Ordnance Survey allocates TOIDs to ensure no duplication arises in the allocation of feature identifiers. Around 440 million TOIDs have so far been assigned, and the database stands at 600 gigabytes in size. OS MasterMap is currently (August 2005) at version 6.

${ }^{21}$ The Open Geospatial Consortium, Inc. (OGC) is a non-profit, international, voluntary consensus standards organization that is leading the development of standards for geospatial and location based services. See: http://www.opengeospatial.org/. The Office of the Deputy Prime Minister, Department of the Environment, Food and Rural Affairs, Ordnance Survey, Cadcorp (geographic information system software provider) and Infoterra (geographic information products and service provider) have all adopted OGC specifications.

${ }^{22}$ Source: The Digital National Framework - helping to integrate geographic intelligence (Ordnance Survey, September 2004) at: http://www.ordnancesurvey.co.uk/oswebsite/aboutus/reports/dnf_overview.pdf.

${ }^{23}$ Ibid. The DNF White Paper (see note 17 ante) was drafted by OS and reviewed by the Expert Group. Today the Expert Group takes on more of a "doing” role.
} 


\section{2. eGovernment policy and the DNF}

It is not a straight-forward task, at this relatively early stage of development, to make firm judgments about UK government responses to the DNF and its potential to support a comprehensive domestic GI strategy. To do so it is first necessary to compare government thinking towards the DNF with the policy statements that underpin the concept of "eGovernment." This is because the main thrust of decisions that the Government may propose for the DNF, as part of its approach to GI strategy, is going to be closely dictated by the objectives and ambitions of its broadly based eGovernment agenda - the overarching policy that directs the Government's response to public sector exploitation of the digital media. ${ }^{24}$ At issue is the extent to which those involved in both sets of policy making have grasped the links between digital and spatial technology. A brief description of the evolution of the concept of eGovernment now follows as a precursor to an evaluation of policy towards GI and the DNF.

\section{(a) The evolution of eGovernment}

The progenitor of eGovernment in the UK, as elsewhere, can be found in the desire to capitalise upon the new medium of the Internet. This resource exploded into global use from the mid 1990's onwards, coinciding with the '.com boom'. Originally the Government focused most of its efforts in meeting the challenge of developing web-based access to government, its agencies and departments. It also encouraged infrastructure development leading ultimately to public broadband access to these services. This pre-occupation can be seen from reports such as Making best use of the Internet, published in April 1995 by the Cabinet Office and the Central Computer and Telecommunications Agency (as it then was). ${ }^{25}$ Such papers, supported by two reports from the National Audit Office entitled Government on the Web I \& II, ${ }^{26}$ offered guidance to government organisations on how to get started and deal with some of the basic issues involved. ${ }^{27}$ This led to several iterations of the Government's web portal now available at www.direct.gov.uk. ${ }^{28}$ It was also the decade prior to the passage of the Freedom of Information Act 2000, which encouraged eGovernment policy makers to speed up online access. ${ }^{29}$ The Government, under John Major, was then still operating a voluntary Code of Practice on Access to Government Information ${ }^{30}$ within the Open Government Initiative. ${ }^{31}$ This emanated from the principles enshrined in the Citizen's Charter. ${ }^{32}$ Another ingredient of the push for an e-Government policy at this time was

\footnotetext{
${ }^{24}$ The European Commission defines eGovernment as "the use of information and communication technologies in public administrations combined with organisational change and new skills in order to improve public services and democratic processes and strengthen support to public policies.” Source: The Role of eGovernment for Europe's Future, COM (2003) 567, p. 7.

${ }^{25}$ Making the best use of the Internet, (Cabinet Office - Office of Public Service and Science and CCTA - The Government Centre for Information Systems, April 1995).

${ }^{26}$ Government on the Web - a report by the Comptroller and Auditor General HC 87 1999-2000 (SO 15 December 1999) and Government on the Web II - a report by the Comptroller and Auditor General HC $7642001-02$ (SO 22 April 2002)

${ }^{27}$ Other published guidance at the time included: Information Superhighway- An update on opportunities for public sector applications in the UK (CCTA, July 1995) and CCTA Government Information Service: How to publish information (CCTA, 1995).

${ }^{28}$ Directgov - the Government's new online portal was unveiled on 1 March 2004, gradually replacing UK Online

${ }^{29}$ Freedom of Information Act 2000 Ch. 36.

${ }^{30}$ Code of Practice of Access to Government Information (Home Office, Freedom of Information Unit, April 1994, $2^{\text {nd }}$ Ed. 1997). A separate code was prepared for the NHS.

${ }^{31}$ Being merely an "Initiative" this stressed the voluntary nature of the policy soon to be legislated via the Freedom of Information Act.

32 The Citizens' Charter was launched by John Major in July 1991 to improve public services. He described the policy as "the central theme for public life in the 1990's."
} 
eCommerce, which the Government declared lay at the heart of its vision for "building a modern, knowledge-driven, economy in the UK." ${ }^{33}$ Its policy was to raise eCommerce as a political priority and to build up understanding of the "opportunities, threats and barriers" to its development, including use within the public sector. ${ }^{34}$

The three strands viz., Internet exploitation, the need for greater freedom of access to information and development of eCommerce within the UK were direct, if not central, influences upon the Government in encouraging it to look for a broader over-arching policy to harness the digital medium. In April 2000, the Government published its strategic plan for the future of public services. This declared that:

\begin{abstract}
"The Information Age revolution has already bought huge changes to both manufacturing and service industries all over the world. It has driven down costs, brought suppliers closer to customers, and made them more responsive to their needs. The Government has launched initiatives to make the United Kingdom a world leader in e-commerce and to make access available to all. This third initiative, e-government, will ensure that government itself will play a full part in this radical transformation of our society. Complementary initiatives for Scotland, Wales and Northern Ireland will extend coverage throughout the UK.”35
\end{abstract}

The paper articulated four "guiding principles" to its eGovernment "initiative." 36 The first, that of “building services around citizens' choices”, considered how to ensure that delivery of government services to the citizen could take place in a form that would make most sense to its 'customers'. The second principle, "making government and its services more accessible", dealt with the need to make those services that could be electronically supplied, available in that format via whatever mix of delivery mechanisms would be best suited to that service. ${ }^{37}$ The third, "social inclusion", set down the benchmark requirement that new services should be "developed so as to be available to all and easy to use.” This would particularly include minority language groups or those with a disability or limited mobility. Finally, the fourth element referred to the need to "use information better.” The Government had recognised that proper management of information could not only produce corporate resources of benefit to business and the citizen, but also deliver improvements in the effectiveness and efficiency of government. ${ }^{38}$ Although not articulated, each of these guiding principles raised implications for GI strategy.

Other reports quickly followed. In May 2000, Successful IT: Modernising the Government in Action $^{39}$ was published identifying new thinking and approaches that might be utilised to secure the desired changes. The Report argued that the Government actually needed to change the way it worked. In September 2000, e-gov: Electronic Government Services for the $21^{\text {st }}$ Century discussed the need for a mixed economy in service delivery that would embrace the private sector more fully. Competition would be encouraged between providers to "stimulate innovation and drive up service quality." 40 In October 2001, the Cabinet Office produced a report on 'channel strategies' for the delivery of government services, designed to encourage the public sector to start thinking about the

\footnotetext{
33 e-commerce at its.best.uk (Cabinet Office, September 1999) para. 1.1.

${ }^{34}$ Ibid., Chap. 8 p. 43.

${ }^{35}$ Modernising government - e-government: A strategic framework for public services in the Information Age, (Cabinet Office, April 2000).

${ }^{36}$ Ibid.., para. 2.

${ }^{37}$ For example, Internet, mobile phone, digital TV or call centre.

${ }^{38}$ Op. cit., note 31 ante., para. 30.

39 Successful IT: Modernising Government in Action (Cabinet Office, May 2000).

${ }^{40}$ e.gov - Electronic Government Services for the $21^{\text {st }}$ Century (Performance and Innovation Unit Report - September 2000). Foreword by the Prime Minister p.3.
} 
criteria for selection of the best means for delivering services to the citizen. ${ }^{41}$ This theme continued in November 2001 when the Public Services Productivity Panel of HM Treasury ${ }^{42}$ called for organisations to embed a 'customer focus' throughout the entire public service sector. This would involve analysis of the trade-off between risk and resource and between competing interests rather than upon the assumption that the "customer is always right." 43

Continuing with the sequence of policy documents, in March 2002 the National Audit Office, responsible for the scrutiny of public spending on behalf of Parliament, examined the risks associated with the successful implementation of electronic services. It noted that approximately 100 major projects, with a total investment of $£ 10$ billion, were in train. Performance in the delivery of IT projects needed to be improved and better business cases built up to support such spending. Allied to this, the Office of the eEnvoy should work with departments to advance good practice as well as the online take-up of services by the public. ${ }^{44}$

In November of the same year a national strategy for local e-Government was published. This identified a framework within which local strategies could be planned for transforming services, renewing local democracy and promoting local economic vitality. ${ }^{45}$ In May 2003, the National Local e-Government Standards Body (LeGSB) was established to help local authorities share best practice through e-standards arising from projects carried out between the latter and their partners. ${ }^{46}$ Later on two follow-up reports were published evaluating progress in local eGovernment development. The first, in December $2003,{ }^{47}$ suggested that good progress was being made towards achieving 2005 targets, whereas the second, published in March 2005, ${ }^{48}$ declared that the momentum was being sustained in completion of an "increasingly sophisticated and complex programme of work."

Continuing with the run of policy documentation, in May 2003, the Office of the e-Envoy issued a consultation document on the development of a policy framework for a mixed economy in the supply of e-government services. ${ }^{49}$ Its purpose was to consult stakeholders on the Government's vision for how this might work. In April 2004, a further strand of e-government operational planning was revealed with the publication of the e-Government Interoperability Framework (eGIF). ${ }^{50}$ This set out technical policies and standards in respect of interconnectivity, data

\footnotetext{
${ }^{41}$ Framework for Channel Strategies: delivering government services in the new economy - draft consultation document (Cabinet Office, UK Online, October 2001)

42 The Public Services Productivity Panel is a small group of senior business people and public sector managers that has been established to identify ways to help improve the productivity of the public sector. The Panel is chaired by Des Browne, the Chief Secretary to HM Treasury.

${ }^{43}$ Customer-focused government - from policy to delivery (Lynton Barker, Public Services Productivity Panel, November 2001) p.6.

${ }^{44}$ Better Public Services through e-government, HC 704-1 2001-02 (Report by the Comptroller and Auditor General, National Audit Office, executive summary.

${ }^{45}$ www.localegov.gov.uk - The national strategy for local e-government (Office of the Deputy Prime Minister, November 2002).

${ }^{46}$ See further locale-Government Standards Body Project Report (local e-gov supported by the Office of the Deputy Prime Minister, October 2005).

${ }^{47}$ www.localegov.gov.uk - One Year On - The national strategy for local e-government (Office of the Deputy Prime Minister, December 2003).

${ }^{48}$ Two Years On: realising the benefits from our investment in e-government- The national strategy for local egovernment (Office of the Deputy Prime Minister, March 2005) Foreword.

${ }^{49}$ Policy Framework for a mixed economy in the supply of e-government services - A consultation document (Cabinet Office, Office of the e-Envoy, May 2003)

${ }^{50}$ e-Government Interoperability Framework, Version 6.0 (Cabinet Office, Office of the e-Envoy 30 April 2004). In May 2004 the National Computing Centre and Institute of IT Training were awarded the contract to create the e-GIF
} 
integration, e-services access and content management considered necessary for coherence and interoperability in the delivery of eGovernement across the public sector.

The last two years has seen the principles outlined in the early flurry of documentation gradually take root across the spectrum. The Office of the e-Envoy, whose primary focus was to "improve the delivery of public services and achieve long term cost savings by joining up online government services around the needs of customers", has been replaced. Since April 2004, the e-Government Unit (eGU), within the Cabinet Office, has existed claiming a very different role viz., "ensuring that IT supports the business transformation of Government itself so that we can provide better, more efficient, public services." In that regard eGU has continued to support the development of the Government Gateway, ${ }^{51}$ which enables departments to communicate via the Gateway and for registered individuals to enter into transactions with the Government via a "single, secure point of entry." Development of services within the Gateway has been modest, but the infrastructure now appears to be in place. In March 2005, the eGU was reported to have set a target of 50 new services on the Gateway in 2005, building on the 47 currently available. ${ }^{52}$ Taking this forward is the eDelivery Team (EDT) which is directly accountable to the Head of e-Government, Ian Watmore, shortly to become Head of the Prime Minister's Delivery Unit from 2006. In May 2005, the EDT published an interactive guide to products, services and solutions intended to accelerate the process towards connected government and best practices in the use of IT. ${ }^{53}$

The progression of the Gateway coincided with the launch of a similar type service for local government - Government Connect. ${ }^{54}$ Meanwhile, the first phase of the electronic Parliamentary Community Network was launched in November 2004, providing a "secure e-infrastructure" for the exchange of information between Government and Parliament. ${ }^{55}$ Similarly, in August 2005, a new phase of the Government Secure Intranet (GSi) project was announced offering 350,000 public sector workers, from 154 government departments, access to a secure common network for sharing information to anyone within the same GSi community. ${ }^{56}$

The Office of Government Commerce (OGc), set up in April 2000 to be independent of HM Treasury, has developed a role seeking best value for money in civil procurement. It supports eGovernment initiatives to the extent that these contribute to planned efficiency targets that seek a $£ 21.5$ billion annual saving by 2007-08. One mapping development that it has brought forward is the Electronic Property Information Mapping Service (ePIMS), supporting the British Standard for spatial datasets for geographical referencing, as well as the DNF and eGIF. ${ }^{57}$ ePIMS displays

Accreditation Authority with responsibility to ensure that departments and suppliers deliver e-GIF compliant solutions. The e-GIF is now on its nth iteration. It is updated annually or thereabouts.

\footnotetext{
${ }^{51}$ The Gateway was launched in January 2001 and is described as "an authentication and routing engine built on open standards.” Over time the Government anticipates that it will handle £5-6 billion of annual government-related transactions.

52 IDABC eGovernment News 23 March 2005.

${ }^{53}$ Interactive Guide to Connected Government Version 1.0 (Filippa Price, e-Delivery Team, 6 May 2005).The EDT described itself as focussing on "delivery and technology innovation in providing the products and services to both central and local government that will enable the Internet to become the primary channel for interaction with government."

${ }^{54}$ Office of the Deputy Prime Minister News Release 2005/0075, 21 March 2005. Exploitation by local government of the Gateway was reported to be disappointing. The new service aims for all local authorities to use the system by 2007. ${ }^{55}$ IDABC eGovernment News 29 November 2004.

${ }^{56}$ First announced on 8 December 1997 by the Prime Minister in his Investing for Growth statement, the service is now supported by Energis, taking over from Cable \& Wireless.

${ }^{57}$ See further e-PIMS - a Background available from the OGC website: www.ogc.gov.uk.
} 
textual information, including precise location and outline of properties on digital maps and permits users to amend and update core property data online.

The Office of Public Sector Information (OPSI) was established in May 2005, within the Cabinet Office, to achieve long awaited reform of the management of public sector information. Her Majesty's Stationery Office (HMSO) retains its status within OPSI in the management of Crown copyright and database rights, while OPSI concentrates on co-ordinating policy standards on the reuse of public sector information. Its declared aim is to "enable our customers to find and re-use information without an in-depth understanding of government structure and the machinery of government." ${ }^{58}$ What was available was a "rich source of valuable information to inform citizens and businesses." 59 To work towards these goals OPSI manages the Information Asset Register (IAR) and, though its inforoute website, lists information resources held by the UK Government. It is encouraging departments to build and maintain their own IAR's on their domestic websites with OPSI controlling formats and standards for operating inforoute. Recent figures as to the growth and levels of content of departmental IAR's do not seem to be available, but 44 public sector organisations now declare a presence in the index. ${ }^{60}$ OPSI also operates the Information Fair Trader Scheme designed to set consistent standards within departments and agencies as to the treatment of potential re-users of public sector information. Full IFTS accreditation involves a verification process, including compliance with the Re-use of Public Sector Information

Regulations 2005 designed to implement Directive 2003/98/EC on the re-use of public sector information. ${ }^{61}$ OS was among the first four verifications to take place in 2003.

\section{(b) Implications of eGovernment policy for the DNF}

It is interesting, up to this point, to note the singular lack of direct reference in the published documentation to the benefits of linking GI strategy to the pursuit of eGovernment objectives. It would seem that the opportunities arising from the reviews that were taking place to engage in the critical thinking required to draw these ideas together was not occurring at a strategic level. ${ }^{62}$ Pockets of fragmented debate focused on specific projects, such as creation of the DNF, rather than the means to exploit it within a policy strategy. So the question arises how the DNF can be promoted to promote such links?

It is evident that the concept of eGovernment - "making the full range of services, which departments and their agencies provide for citizens and businesses, accessible electronically .... and harnessing new technology, such as the Internet and intranets, to improve their operational efficiency in delivering services and carrying out their core activities”63 - sends a strong message to all departments and agencies. They should examine their service portfolios and look for ways of harnessing the digital medium to improve the quality of their outputs. But the policy was also linked to the transformation of government. eGovernment should not be seen as an end in itself. In addition to the desire to provide better access to services for the citizen, its pursuit was also perceived as a means of fulfilling tangible e-business objectives, such as provision of better

\footnotetext{
${ }^{58}$ www.opsi.gov.uk “About the e-Services Team.”

59 Ibid.

${ }^{60}$ As at 14 October 2005.

${ }^{61}$ Directive 2003/98/ECof the European Parliament and of the Council of 17 November 2003 on the Re-use of Public Sector Information, (OJ L345/90, 31.12.2003).

${ }^{62}$ See for example Transport, Local Government and the Regions - Tenth Report- Ordnance Survey (HC 48 Session 2001-02, 22 June 2002) in which many of the activities were reviewed. See also Ordnance Survey - the Economic Contribution of Ordnance Survey GB (Oxford Economic Research Associates (OXERA) 24 September 1999) which also highlighted the benefits of GI and OS data.

${ }^{63}$ Op. cit., note 43 ante, para 1.1 .
} 
information. This involved greater use of electronic media for knowledge sharing and data connectivity and more efficient business processes such as records management. ${ }^{64}$ Giving OPSI the responsibility to require the creation of departmental public IAR's, and to render them centrally searchable via Inforoute, was an important step forward. The hope was that this would gain the attention, particularly of officials, to the need for a fundamental appraisal and assessment of what assets they were holding and what could be done with them in digital format.

But more than that the Government was also, in developing its eGovernment agenda, beginning to focus on the policies and standards required to achieve interoperability in information flows across the public sector and beyond. The application across government, since the year 2000, of eGIF ${ }^{65}$ as the "technical cornerstone of eGovernment policy", the requirement that all official documents should, thereafter, adhere to the eGovernment Metadata Standard (eGMS) ${ }^{66}$ (listing the metadata ${ }^{67}$ requirements for content), and the development of a common, secure hub viz., the Government Gateway ${ }^{68}$ (providing a central access point for national, regional and local online services), all contributed to what the Office of the e-Envoy (as it then was) declared in 2003 was "one of the most advanced eGovernment infrastructures in the world.”69

So has the concept of "better public services through e-government" successfully transferred itself to the development of the DNF and the beginnings of a strategy for GI? To recap, the DNF is more a template than a "data silo" It is an industry standard for integrating and sharing business and geographic information from multiple sources. ${ }^{70}$ It comprises "the National Grid linked to the Global Positioning System (GPS), height data, detailed topographic information and unique identifiers on features." 71 The establishment of principles and operational rules to the process of layering geo-referenced information from multiple sources is what gives it a value that takes it beyond specific applications into the realm of a national resource. In particular, by enabling a wide range of applications to be supported, dependent directly or indirectly upon geographical data and thereby establishing a reliable and integrated reference base for geographic information, the eeconomy can be supported. ${ }^{72}$

But more than that, it can be argued that the DNF can, in fact, extend the benefits of digital resources and eCommerce to those parts of the business community that have yet to take full advantage of them. The recent launch of Google Earth ${ }^{73}$ and Microsoft's Virtual Earth and several other products ${ }^{74}$ are harnessing aerial photography, satellite images and digital photographs of buildings and street scenes to achieve in Microsoft's words:

\footnotetext{
${ }^{64}$ Ibid., p. 21.

${ }^{65}$ See further note 49 ante.

${ }^{66}$ E-Government Metadata Standard e-GMS Version 2.0 with XML syntax (Office of the e-Envoy, 8 December 2003).

${ }^{67}$ Metadata describes the content and form of any data and can be added to or attached to a web page, file or database. See further www.govtalk.gov.uk. In addition to metadata standards a controlled vocabulary - Integrated Public Sector Vocabulary (IPSV) has been introduced to make identification of relevant material easier to accomplish.

${ }^{68}$ See ante, note 51.

${ }^{69}$ Government Gateway - Government Transactions through the Internet (Office of the e-Envoy, 2003).

${ }^{70}$ www.dnf.org/Introduction/WhatIsDNF.htm. See further section 1 and notes 3-18 ante.

${ }^{71}$ UK Digital National Framework (DNF) for Geographical Information (Cover pages Technology Reports, 19 October 2001) at xml.coverpages.org/dnf.html.

${ }^{72}$ It is true to say that the concept and definition - while still about joined up geography - has moved on slightly over the last five to six years. The best source of information on this can be found at www.dnf.org.

${ }^{73}$ Google Earth is a 3D graphics application enabling the viewing of aerial photography and satellite images to show views of the Earth from above in great detail. Search 'Google Earth' at en.wikipedia.org.

${ }^{74}$ For example Amazon’s A9.com Yellow Pages that contains 20 million images from 10 cities including New York, Los Angeles, Boston, San Francisco, Phoenix etc.
} 


\begin{abstract}
“a deeply immersive local search experience in which [users] can easily find, discover and plan activities relevant to a location. It takes information consumers want (e.g. weather, traffic, hotels, restaurants, entertainment and photos) and brings it together in ways that enable people to answer the question 'What's it like there?' MSN Virtual Earth” will provide a core set of reference points such as maps, aerial imagery, photos, consumer and business directories, and ratings and reviews, and allow the broader community of consumers and businesses to contribute their own location-specific information to create an always expanding, dynamic and relevant local search experience",75
\end{abstract}

A developed, evolving and maintained geospatial resource will boost the capacity of both local and national economies, not only in the growth of the business and consumer base likely to adopt the medium, but also among those working to enhance its technological capabilities. It will also provide a platform for the private sector to develop spatial resources of the kind just outlined.

In Great Britain the task of initiating the DNF has rested, in the main, with OS with the Expert Group now taking more ownership of activities. As Britain's national mapping agency OS has been contributing to the process by re-engineering the National Topographic Database - the computerised 'master map of Britain' - itself a major component of the DNF, as well as developing its own 'DNF compliant' product - OS Master Map. ${ }^{76}$ OS has the necessary technical expertise and experience to enable it to co-ordinate the expansion of the DNF. Having come into existence as a government department in 1791, and having celebrated two centuries of service to the British Government as its national map maker, OS became an Executive Agency of the Department of the Environment on 1 May 1990. As such, it may not directly set policy or dictate the level of resources at its disposal, but it did gain greater freedom to implement policy in the manner it considered best. On 1 April 1999, OS took a further step towards independence when it secured full Trading Fund status. ${ }^{77}$ This took it outside the normal Supply process managed by HM Treasury. On that date ministerial responsibility for OS, as a government department, transferred to the Deputy Prime Minister. As a Trading Fund operator, OS is mandated to pay its way from the income generated from its commercial activities. In its case, this must come from the sale of maps and spatial datasets, as well as from licensing agreements reached with commercial partners. As its shareholding department, OS must also make a return, through dividend payments, to HM Treasury. ${ }^{78}$

In December 2000, in its first year of trading, OS announced the first profit in its 209 year history with a $£ 12.7$ million trading surplus on a turnover of $£ 99.6$ million for the 1999-2000 financial year. Revenue from electronic data now accounted for some $80 \%$ of OS turnover. OS maintains that profits are necessary to fund the major investments in the databases that are required year on year. Of potential significance for GI policy development, was a reported figure suggesting that the national mapping agency's spatial data underpinned up to $£ 136$ billion worth of economic activity in the UK - "everything from crime-fighting and conservation to marketing and mobile phones."79

\footnotetext{
${ }^{75}$ See msn Virtual Earth Frequently Asked Questions, July 2005 at: www.microsoft.com/presspass/events/mappoint/msnve.mspx

${ }^{76}$ See section 1 and notes 7-23, ante.

77 See: The Ordnance Survey Trading Fund Order 1999 (SI 1999 No. 965). Trading Funds are established under the Government Trading Funds Act 1973, as amended by the Government Trading Act 1990 and the Finance Acts 1991, 1993 and 2001.

${ }^{78}$ Under the framework document presented to Parliament by the ODPM in July 2004 OS is also required to make an average return of $5.5 \%$ on the capital it employs - currently around $£ 40$ million.

${ }^{79}$ Ordnance Survey News Release 21 December 2000. See also: Annual Report and Accounts 1999-2000 HC26 (SO 20 December 2000).
} 


\section{Improving quality and access to public sector geo-spatial information}

\subsection{National interest mapping services}

On 13 October 1999, as part of the conversion from Executive Agency to Trading Fund, OS entered into a 'not-for-profit' National Interest Mapping Services Agreement (NIMSA) with ODPM. This covered "activities that cannot be delivered on a full cost recovery basis under the Trading Fund operating model of Ordnance Survey." 80 The agreement for seven years, to March 2006, focuses on pursuit of mapping activities in the national interest that could not be justified on commercial grounds - for example, the mapping of remote areas of the country that have little commercial return on cost, but high strategic value. The existence of data sets of this kind might assist significantly in an "emergency situation", such as during an outbreak of livestock disease when specialised maps might be required at very short notice. ${ }^{81}$

In addition to mapping services and the underpinning of mapping infrastructure, NIMSA also defined "national interest" in terms of national consistency of "content, currency and style of mapping." Two needs arose, the first being the supply of information for defence purposes. The second related, for example, to the development and promotion of consistent data collection based on a common topographic framework where "significant economic benefits would be generated." ${ }^{2}$

It can be argued that the overall strategy of NIMSA is in tune with eGovernment ambitions to harness new technology to improve public sector operational efficiency and service delivery through its interpretation of the national interest in the delivery of mapping and related services. Whilst NIMSA never engaged with the DNF, utilisation of the latter underpinned many of the activities selected for action under the agreement for which a return on investment, in pure revenue terms, was not a priority. NIMSA also offered much needed bridging funding to an emerging OS as a fledgling Trading Fund and eBusiness operator. This resulted in $£ 70$ million being invested in "national interest" projects during the first five years of the agreement. ${ }^{83}$

In many respects, therefore, the partnership between government and OS, as orchestrated by the ODPM since 1999, has been a success. In addition to the mapping services, already outlined, OS has also supported other aspects of the Government's modernisation programme. For example, on 1 April 2003, the two parties - OS and ODPM - entered into a Pan Government Agreement (PGA) to supply central government with access "to a portfolio of OS digital map products." 84 This three year agreement is designed to help central government make better use of geographic information. By 2004, evidence showed that more than 200 central government customers had utilised the agreement. ${ }^{85}$ In the Home Office for example:

"the PGA is currently helping the Home Office to deliver more integrated government services by centralising the management of OS data. Prior to the PGA, the Home Office had a number of different supply agreements

\footnotetext{
${ }^{80}$ Atkins Management Consultants, Consultation on the Future of the National Interest Mapping Services Agreement (NIMSA) (ODPM, May 2005).

${ }^{81}$ V. Lawrence, The changing role of national mapping organisations: A case study of Ordnance Survey at: www.gisdevelopment.net/

${ }^{82}$ NIMSA Annual Report 2002-03 p.1.

${ }^{83}$ The contribution to OS in the 1999-2000 was £14.6 million; in 2000-01, £13.5 million; in 2001-02, £16 million; in 2002-03, £12.5 million; and in 2003-04, £12.8 million. £13.2 million has been set aside for 2005-06.

${ }^{84}$ Report on the Annual Review of the Performance of the Pan Government Agreement (PGA) for the supply of Ordnance Survey (OS) Data to Central Government (Inter-Governmental Group on Geographic Information (IGGI) 5 November 2004), p. 4.

${ }^{85}$ Ordnance Survey - Annual Report and Accounts 2003-04, HC 856 (The Stationery Office, 8 July 2004) p. 32.
} 
and data was distributed across a number of separate systems. Adopting a common agreement and centralising the storage and management of the PGA is helping the Home Office to provide more integrated, joined up services internally." 86

In May 2005, a new Mapping Services Agreement (MSA) ${ }^{87}$ was also reached with local government. This was the third or fourth such agreement to be entered into, but the first through European competitive tendering processes.

By this Agreement OS would facilitate access to current digital mapping and geographic data, such as OS MasterMap, to more than 500 local government organisations. The aim is to "use the power of geography to meet eGovernment targets" ${ }^{\text {"8 }}$ and to develop economies of scale in the development of better front-line services. This would take place through access to consistent topographic, address and integrated transport network data among a wide range of products.

With both the current PGA and NIMSA agreements due to expire in March 2006, attention has begun to focus, over the past year or so, upon the renewal of these agreements and negotiating the scope of any commitments likely to be involved in any such extension. In the case of the PGA, overall responsibility for the current agreement and its renewal rests with a steering group of the Intra-Governmental Group on Geographic Information (IGGI) - a body established in 1993 to improve liaison and best practice exchange in the use of geographic information. On the Government side the negotiation rests with the Planning and Land Use Statistics Division of the ODPM. The latter has announced that "it is intended to work towards a further PGA on the expiry of the current agreement.",89

Of much greater significance, however, is the broader question of the future funding and direction of "national interest mapping services" that will, unless renewed, no longer be supported once NIMSA completes its seven year term in 2006. In the build-up to the ODPM's review, opinions began to be expressed by OS and others as to priorities for the future structure and content of the agreement. One of the most significant papers was delivered in November 2004 by OS and the Association for Geographic Information (AGI). ${ }^{90}$ The latter was established in 1989 following a recommendation to government ${ }^{91}$ that a forum should be created for the exchange of ideas on the development and handling of geographic information. ${ }^{92}$ In their submission, the two organisations identified what they saw as a fundamental gap in service provision. While the paper did not dispute that a framework for integration of GI of all kinds existed within DNF there were, nevertheless, serious shortcomings in the discovery of data resources that were geographically referenced.

\footnotetext{
${ }^{86}$ Op. cit., note 81 ante, p.58.

87 The MSA was initiated by Local Government Information House (LGIH) part of the Improvement and Development Agency (IDeA) working on behalf of the local government community. The agreement, which follows on from the previous 10 year service level agreement, covers all district, county and unitary councils, metropolitan borough councils, London boroughs, national park authorities and some emergency services such as local police and fire. It is hoped to save more than $£ 100$ million over a four year period.

88 AGI, Agreement sealed on mapping services for local government, 3 June 2005.

89 ODPM website at: www.odpm.gov.uk/stellent/groups/odpm_planning/documents/page/odpm_plan_607355-02.hcsp

${ }^{90}$ An independent Review of the sustainability of a UK metadata service for geographically related information (jointly commissioned by AGI \& Ordnance Survey, November 2004) p.2.

${ }^{91}$ Handling Geographical Information - Report to the Secretary of State for the Environment of the Committee of Enquiry into the handling of Geographic Information (The Chorley Report) (HMSO, 1987).

${ }^{92}$ AGI is now a multidisciplinary organisation "dedicated to the advancement of the use of geographically related information. It covers all interest groups including local and central government, utilities, academia, system and service vendors, consultancy and industry. It aims to increase awareness of the benefits brought about by the new technology, and assist practitioners in the attainment of these benefits." See:

www.agi.org.uk/bfora/systems/xmlviewer/default.asp?arg=DS_AGI_ABOUTART_21/_firsttitle.xsl/4
} 


\subsection{Metadata standards}

The paper argued that a significant problem existed with the volume - up to $80 \%$ of all government data according to some estimates - of data that was geographically referenced or related. Much of this was not being exploited because it was "not known about, not accessible, not affordable or not available" in a form that was readily usable. ${ }^{93}$ For users that needed to undertake some form of location analysis the problem was more acute. It asserted that, "not only have they got to discover the right type of data, they also need to find if that data covers their area of interest and is geographically referenced in a way that can be used in their analysis." ${ }^{94}$ Such spatial searches were not well supported by current metadata standards i.e. those which describe data resources in a structured form to make them more readily discoverable. ${ }^{95}$

The development of metadata services in the UK has evolved over nearly 20 years now. The Chorley Report in $1987^{96}$ had called for the creation of data registers of spatial data as a means of identifying relevant datasets linked to information on content and access. The proposal, in 1995, to establish a National Geospatial Data Framework (NGDF) here was a reflection of what was happening in the US in the form of the National Spatial Data Infrastructure (NSDI). The view was that the UK should have one despite the fact that no one really knew what it was - hence its failure! ${ }^{97}$ This was not a physical framework and did not supply services, datasets or products as such, but rather set out to define the UK's approach to spatial data in terms of standards, metadata and access. The emphasis was on developing projects rather than the more centralised approach of base datasets. ${ }^{98}$ An initial attempt, which predated NGDF by several years, used simple and locally developed metadata standards relating to some 600 departmental datasets (SINES) to create a service. $^{99}$ SINES, however, proved difficult to maintain, given the need to try and create a single format for the metadata and was superseded in July 2000 by “askGIraffe.” To get it started askGIraffe was supported initially by the Invest to Save fund maintained by HM Treasury and then by NIMSA. Its aim was to become the "first choice web site" for access to geospatial information metadata generated by both the public and private sectors in the UK. It represented an improvement on SINES since it contained a data locator search facility via a map, index or keyword, as well as a data integrator designed to act, in effect, as a search engine for GI. ${ }^{100}$

The NGDF, having been originally launched at AGI'95, had its management and operation transfer to AGI in September 2001. OS staff continued to support the framework for the duration of the agreement until April 2002 when the askGIraffe service was re-branded GIgateway. ${ }^{101}$ This

\footnotetext{
${ }^{93}$ Op cit., note 90 ante p.3.

94 Ibid.

95 See note 67, ante.

${ }^{96}$ See note 91 ante

97 The National Geospatial Data Framework (NGDF) was the name of the UK geospatial data infrastructure when launched at the AGI annual conference in 1995. Its aim was to "facilitate the unlocking of geospatial information (GI) through enabling better awareness of data availability, improving access to the data and integrating data by encouraging the use of standards.” For the NSDI see: www.fgdc.gov/nsdi/nsdi.html.

${ }^{98}$ Clare Hadley and Lionel Elliott, National Geospatial Data Framework (NGDF) - The UK Model at: http://www.gisdevelopment.net/policy/gii/gii0004.htm

99 The Spatial Information Enquiry Service was a meta database of spatial datasets held in UK government departments and agencies. It operated as a telephone service, subsequently extended to email and online searches. Until superseded SINES was run by the OS on behalf of the Department of the Environment.

${ }^{100}$ Source: Spatial Data Infrastructures in the United Kingdom: State of play Spring 2004 - Country report on SDI elaborated in the context of a study commissioned by the EC (EUROSTAT \& DGENV) in the framework of the INSPIRE initiative (Spatial Applications Division, K. U. Leuven Research \& Development, August 2004) p. 11.

${ }^{101}$ Not to be confused with Government Gateway - the centralised registration service for eGovernment services in the UK. See note 51, ante.
} 
claimed to be an improved service that was beginning to tackle the problem of access to geospatial data. Via a single search query a user could initiate a search that "simultaneously searches the metadata databases of several major geospatial data providers, and returns catalogue results within seconds." ${ }^{102}$ This success was credited to the use of a new metadata creation tool MetaGenie V.1.0, released officially in February 2004. In the summer of 2005, a Version 2.0 was launched to implement the new UK GEMINI Discovery Metadata Standard published in October 2004. ${ }^{103}$ This superseded the Gigateway metadata specification - the NGDF standard. UK GEMINI is the product of collaboration between AGI and the eGovernment unit of the Cabinet Office ${ }^{104}$ and has been designed to fit the eGMS standard (within eGIF) ${ }^{105}$ as well as the International Standards Organisation (IS0 19115) ${ }^{106}$ schema for describing geographic information and services. As a result, an application profile has been created that will enable "all organisations involved in creating and managing geo-spatial data sets ... [to develop] ... a metadata catalogue which maps to a common international standard.”107

\subsection{A National Metadata Service}

The need for spatial data infrastructure (SDI) in the UK would now appear to be generally accepted subject to a desire for improvement. A strong impression therefore emerges that the components exist for fulfilment of eGovernment objectives provided some strategic oversight can be included. The DNF template exists but not in terms of metadata. Modernisation of metadata standards is underway and is supported by the drive to deliver interoperability and connectivity of information and eService provision within government and in its dealings with the public. The opportunity, therefore, exists to invest further in the utilisation and development of this infrastructure. At issue, of course, is what sort of the agenda can be arrived at to take this forward, how fast it can be implemented and where the funding and government leadership will come from to support it.

High on the list of priorities for AGI and OS in their review ${ }^{108}$ was the need to tackle the lack of co-ordination in UK metadata services. Despite the progress that had been made in moving towards more 'geo-spatial friendly' standards for metadata, a national metadata service was needed to coordinate their adoption so as to gain better access to data that was geographically referenced. The paper asserted that a "mountain" - probably "tens of thousands" of geographic data sets held by government - was still not being exploited because their identity was not known. In addition, among the 4000 or so metadata records for data sets in the UK, accessible via GIgateway, some were out of date and others were either inadequate or inaccurate. A neutral, publicly funded national metadata service offered the best opportunity to tackle some of these problems and to educate the custodians of public sector information as to the importance of this kind of data housekeeping. However:

\footnotetext{
${ }^{102}$ Lee West \& Louise Schofield, GIgateway 2004-2005: A Year in Review, p.3 at: www.gigateway.org.uk.

${ }^{103}$ UK GEMINI Standard Version 1.0 - A Geo-spatial Metadata Interoperability Initiative (Cabinet Office eGovernment Unit \& AGI, 12 October 2004).

${ }^{104}$ And prior to that the Office of the e-Envoy working with UK Data Archive.

${ }^{105}$ See notes 50, 64 \& 65 ante.

${ }^{106}$ ISO 19115: 2003 Geographic Information - Metadata (International Organisation for Standardization). It provides "information about the identification, the extent, the quality, the spatial and temporal schema, spatial reference and distribution of digital geographic data." Its principles can be extended to "many forms of geographic data such as maps, charts and textual documents as well as non-geographic data.” ISO is the world's leading developer of international standards.

${ }^{107}$ Gigateway FAQ’s at: www.gigateway.org.uk/moreinformation/faq.html.

108 See ante, note 90 .
} 


\begin{abstract}
"Without a major effort to get organisations to document and manage their data resources, a national metadata service will always struggle because the creation and the maintenance of the metadata will not be seen as a core activity. In the case of government, which sits on so much of the nation's data asset, this is going to require both 'sticks' in the shape of more coherent legislation and 'carrots' provided by funding, training tools, guidance and standards." 109
\end{abstract}

The continuing problems with metadata were underlined in May 2004 by IGGI in a report published by ODPM. ${ }^{110}$ This identified the significant ongoing requirement for holders of public sector information to modernise their metadata for the datasets under their charge. The report suggested, for example, that much work needed to be done to bring the metadata up to date. Maintenance of metadata was an ongoing responsibility of departments and agencies and attention to this problem would need resourcing. ${ }^{111}$

There is no sign at this point that the Government is prepared to consider this proposal in the form it is presented. Responsibility for the delivery of eGovernment is firmly in the hands of the eGU within the Cabinet Office and with the ODPM and HM Treasury so far as the terms for any renewal or extension of NIMSA is concerned. Given the link between the quality of metadata within public sector geospatial information and national interest mapping services one might expect this issue, if it is to be taken up, will feature in the renewal negotiations. ${ }^{112}$

\title{
3.4 The future of NIMSA
}

In May 2005, the ODPM published the results of its Consultation on the future of NIMSA. ${ }^{113}$ This involved online public consultation over a 12 week period during which 300 responses were received as well as 30 interviews conducted with selected stakeholders. Surprisingly, the process uncovered a general level of ignorance as to the role and scope of NIMSA funding offered to OS, even among users of GI. However, 96\% of respondents called for either an expansion of the services funded under NIMSA or an extension of the existing agreement. Respondents in favour of change recommended that NIMSA funding might be used to improve data and metadata standards, as well as "added value" mapping activities such as flood maps. They also speculated whether funding could be found to meet the cost of a new 'data sharing' licence to meet the cost of greater dissemination of data between both the public sector and beyond. However, among the new activities highest rated for NIMSA funding support was the collection of aerial imagery for use in the process of baseline mapping and its digital counterpart. This offered a range of IT and geographic information systems (GIS) applications. In addition, greater investment in GPS resources would support the OS Positional Accuracy Improvement Programme (PAI), designed to improve compatibility between GPS-based surveys and OS baseline data. Investment in both GPS activities as well as national SDI was important as these were the "enablers" of UK GI, as opposed to simply "products and services in their own right." 114 Concerns remained, however, that the ongoing cost of migration to OS MasterMap and the PAI programme continued to produce a "negative impact on the relationship between OS and their customers" as did data quality in the current deliverables and the length of time taken for new features to appear on the map base. ${ }^{115}$

\footnotetext{
${ }^{109}$ Ibid., p. 38.

${ }^{110}$ Principles of Good Metadata Management, $2^{\text {nd }}$ Edition, (IGGI, ODPM, May 2004).

${ }^{111}$ Ibid., pp. 13-14.

${ }^{112}$ Within reason - very high costs of maintenance versus low level usage is not greatly cost effective.

113 See note 80 , ante.

${ }^{114}$ Ibid., p. 32.

115 Ibid., p. 36.
} 
The Consultation noted that oversight of the agreement was in the hands of the NIMSA Review Group (NRG), comprising representatives from both OS and ODPM. Its remit was to "work in the public interest to ensure that mapping services are provided to agreed standards and represent value for money to the nation." 116 Through its efforts, funding during the current agreement had been carefully allocated to a range of tasks. From the outset, the focus had been on the content, currency and quality of the NTD ${ }^{117}$ - the data repository from which the mapping products of OS derived, although only marginally engineered within the DNF. In particular, this related to the maintenance of the less commercial rural and moorland mapping base. ${ }^{118}$ Under the scrutiny and direction of NRG, funding for the latter had increased, most significantly for PAI, compared with the overall investment in OS' underlying database infrastructure. NIMSA also supported services to specific users, including emergency help lines, educational and teacher training activities, advice to the Boundary Commission and financial support for the AGI GIgateway metadata search engine. ${ }^{119}$

Respondents were also critical of these user services. The 'helpline' service operated by OS was not used or needed and could be handled by the 'blue light' and civil contingencies' services themselves. Also, while OS had a role in education services, these could be more directly linked to the departments and bodies responsible for education provision. The relationship between OS and the Boundary Commission, relied on heavily by local authorities, was important as it facilitated the creation and amendment of administrative boundaries. However, there were issues that went beyond the scope of the Consultation as to inefficiencies in current processes and accounting methods. Considerable scope for improvement existed, particularly in the practice of reliance on maps in hard copy (offline) format. Finally, there was concern that the GIgateway metadata service lacked a "critical mass of users to encourage wider uptake." 120 Problems also remained as to the scope and relevance of metadata available and as to interoperability and standards among similar metadata services. $^{121}$

Since this was a report prepared by management consultants for the ODPM, rather than by the department itself, it could only offer suggestions to the Government as to how it might respond. The Consultation concluded that:

"In considering the future of NIMSA, it is clear that a distinction needs to be made between support for Ordnance Survey and support for National Interest Mapping. Both are considered worthy, but it can no longer be considered axiomatic that support for one implies support for the other."122

A concern here related to the need for OS to account separately for both NIMSA and non-NIMSA activities. This was necessary to prove that there had been no cross-subsidy between the commercial aspects of OS' operations and fulfilment of its NIMSA obligations. The Consultation, whilst recognising this concern, nevertheless suggested that at an operational level this obligation might create “a barrier to process efficiencies.” The need for OS to maintain distinct 'flow lines' for

\footnotetext{
${ }^{116}$ Ibid., p. 7.

${ }^{117}$ See note 20 et seq. ante.

118 This includes continuous \& cyclical updates of rural and moorland mapping data as well as updates of the coastline, administrative boundaries, rural road centrelines and grid references to new rural postal addresses.

119 See note 101 et seq., ante.

${ }^{120}$ Op. cit., note 80 ante, p. 37.

${ }^{121}$ Ibid. Services such as Go-Geo operated by EDINA at University of Edinburgh (targeting academic users of geographic information) and the multi agency MAGIC service (data sets relating to the natural environment). Some evidence that AGI, the operators of GIgateway, are aware of the issues comes from their review of 2004-05 in which they declare that in 2005-06 the emphasis will be on the quality not quantity of metadata available on the database. EDINA is the ancient poetic name for Edinburgh and is a Joint Information Systems Committee (JISC) funded national datacentre.

${ }^{122}$ Ibid., p. 40.
} 
NIMSA funded activities could place major obstacles in the way of the 'collect once, use many' approach to survey data. To be used most efficiently, the latter needed to be exploited for all relevant purposes in the development of mapping products. ${ }^{123}$ Whilst the Consultation acknowledged that clear support existed among users for the continued public sector funding of mapping activities, it also suggested that such support extended "beyond the current remit of Ordnance Survey" to a wide range of organisations in the public, private and 'third sector' that undertook relevant activities. As such, OS should no longer be considered "the exclusive agent of national interest in mapping.",124

It may be that this finding has left the ODPM with much to think about. With just a few weeks of the existing agreement left to run no formal response has yet been published as to its future. This is in sharp contrast to the confident tones of an OS media release in September 2004 that said that ODPM would use the Consultation to inform a decision on NIMSA "early in 2005." 25 Planning Minister Keith Hill MP was also quoted as saying:

"We have world class mapping. We must make sure that it continues to meet user needs. If some essential requirements are not commercially viable then we need to see how Government can help out.” 126

On the other hand OS was not itself certain what the future would hold. The broad options were to continue NIMSA "along the same lines as now, make revisions as required; reduce or increase the range of activities covered; or stop the agreement altogether.” The latest position as announced is a review of the agreement inviting "market soundings" as indicated on the ODPM website. The date for submission of comments closed in mid December 2005. ${ }^{127}$ ODPM is committed to making its plans public once responses have been considered. It may be that more critical thinking than was originally envisaged needs to be undertaken before a clear policy emerges. The complexities of accounting for the different pockets of investment in public interest services, particularly now that OS is operating as a Trading Fund, may have clouded the negotiations, as well as the reported diversification in involvement in "national interest" activity. Also, in the midst of the review of what to with NIMSA in 2006, came the additional problem of the failed negotiations for a National Spatial Address Infrastructure (NSAI).

\subsection{The proposal for a National Spatial Address Database}

In May 2005, coinciding with the launch of the new local government Mapping Services Agreement, the ODPM, the Improvement and Development Agency (IDeA) ${ }^{128}$ and OS announced a prospectus for a national spatial address database for the UK. ${ }^{129}$ The aspiration to develop a NSAI, bringing together all existing sources of address information into a single entity, sits squarely within eGovernment objectives. Not only would it become a key referencing point and resource within the DNF, but the proposal, as outlined, would also conform to standards for information

\footnotetext{
${ }^{123}$ Ibid., p. 9. One example lies in the collection of aerial imagery which could be used "both for baseline survey purposes and for generating digital images for further resale. For Ordnance Survey, the need to prevent such crosssubsidy prevents the full realisation of such efficiencies.”

${ }^{124}$ Ibid., p. 40.

${ }^{125}$ OS Consultations begin on future of NIMSA 20 September 2004

126 Ibid.

${ }^{127}$ See: www.odpm.gov.uk/index.asp?id=1144581 added to the website on 25 November 2005.

${ }^{128}$ IDeA "was created by and for local government in England and Wales in 1999. It is independent of central government and regulatory bodies and accountable to local government through a board of directors comprising local government councillors and other stakeholders. The IDeA is a company wholly owned by the Local Government Association (LGA)." Source: www.idea.gov.uk.

${ }^{129}$ Towards the National Spatial Address Infrastructure - Outline Prospectus (ODPM, IDeA and OS, May 2005).
} 
handling being developed by the Office for National Statistics (ONS) as part of its Geographic Referencing Framework. ${ }^{130}$ By complying, too, with both eGIF and eGMS standards, ${ }^{131}$ it was suggested that the NSAI would be in a strong position to support a "wide range of services delivered by central and local government." Improvements to the address base would support "the processing of benefits claims, the management and collection of local taxation, the next population census, as well as supporting the delivery of services such as police, fire and social care.” It would also “complement arrangements” for local authorities under the new MSA. ${ }^{132}$

The Prospectus envisaged that the NSAI would be developed and run by OS and would incorporate and build upon existing address datasets found in Local Land and Property Gazetteers (LLPGs), the National Land and Property Gazetteer (NLPG), the National Street Gazetteer, the PostCode Address File (PAF) and AddressPoint. ${ }^{133}$ NSAI would also draw upon the "expertise of stakeholders, including local authorities, Royal Mail Group plc, ONS and the Valuation Office Agency."134 It would comply with a proposed new British Standard for addresses ${ }^{135}$ and incorporate new Unique Property Reference Numbers (UPRN) developed from the Gazetteer datasets. These would be shared in a publicly available "cross referencing table" linked to AddressPoint, as well as Royal Mail Unique Delivery Point Reference Numbers (UDPRN), topographical indicators (TOIDs) within OS MasterMap, ${ }^{136}$ Valuation Office Agency Unique Address Reference Number (UARN) and Unique Street Reference Numbers (USRN).The Prospectus envisaged a roll out of the database over a 30 month period, starting with England and Wales and later Scotland and Northern Ireland. ${ }^{137}$

The response to the Prospectus came from two directions. First, the parties involved, in particular OS and IDeA, began negotiations for the transfer of ownership of the NLPG to OS as an input into the NSAI. This was in line with preliminary consultations, led by ODPM, to agree funding and governance arrangements for the NSAI through prior discussion with representatives from both central and local government. A governance structure needed to be put in place "to ensure that the development of the NSAI was championed effectively, had clear strategic direction and was developed in partnership between stakeholders and the lead supply agency."138 A 'Ministerial Champion' for the NSAI - ODPM Minister for Local Government - would support the development. This was logical since ODPM had an "overarching role” in relation to geography and land use statistics, led on local government policy and links with central government, had Ministerial responsibility for OS and was the lead agency for the PGA on provision of GI. Supporting the Minister would be a Steering Group, chaired by ODPM, comprising senior representatives of the stakeholders. Reporting to it would be two parallel groups - a Stakeholder Partnership Group, responsible for ensuring delivery of the agreed specification to the agreed

\footnotetext{
${ }^{130}$ ONS is developing its Geographic Referencing Infrastructure (GRI) to deliver its geographic referencing framework. It will support the collection, processing, analysis and dissemination of statistics, and as such is a key plank of ONS's Statistical Modernisation Programme. See further: www.statistics.gov.uk/geography/gri.asp.

${ }^{131}$ See notes 103-107, ante.

${ }^{132}$ Planning the National Spatial Address Infrastructure (IDeA press release, 26 May 2005).

${ }^{133}$ ADDRESS-POINT is a dataset that uniquely defines and locates residential, business and public postal addresses in Great Britain. It is created by matching information from Ordnance Survey digital map databases with more than 26 million addresses recorded in the Royal Mail ${ }^{\circledR}$ Postcode Address File $\left(\mathrm{PAF}^{\circledR}\right)$.See further: www.ordnancesurvey.co.uk/oswebsite/products/osmastermap/address/

${ }^{134}$ Op. cit., note 125 ante, pp. 6-7.

135 BS7666:2005.

${ }^{136}$ See notes 7-23, ante.

137 The first "cut" of the NSAI would become available eight months after agreement with the final structure to be announced after 18 months. The full NSAI would be operational after 30 months.

${ }^{138}$ Op. cit., note 129 ante, p. 13.
} 
timetable and a Management Group - providing external operational project governance. OS, as the lead supply agency, would also provide a project control team to be managed internally. ${ }^{139}$

Surprisingly, the Prospectus reveals remarkably little information about budgets and funding. ${ }^{140}$ No doubt this issue surfaced strongly in the period before the consultation was published. It may be that the ODPM was satisfied that this issue would be resolved during the post publication negotiations between the stakeholders. If this was the plan then it was to lead to disappointment. On 11 August 2005 OS issued this statement:

\begin{abstract}
"Following the publication of the outline prospectus on the National Spatial Address Infrastructure (NSAI) by ODPM in May 2005, the Improvement and Development Agency (IDeA) and Ordnance Survey (OS) have been in discussions on the agreements necessary to underpin the proposed infrastructure. OS and IDeA have announced today that plans to transfer ownership of the National Land and Property Gazetteer (NLPG) to OS as an input into the NSAI had not reached agreement within the original timescales. Further negotiations on the transfer have been suspended whilst all parties consider the implications for the future.”"141
\end{abstract}

The statement continued that detailed consideration of all aspects of the proposed arrangements had not secured agreement as to how NLPG could become part of the NSAI, given that the latter would be available under a Crown copyright licence. ${ }^{142}$ This, presumably, was a reference to how distribution of the revenues obtained from users of the NSAI would be distributed among the stakeholders, including IDeA and OS. Perhaps it was also about what the implications of Crown copyright regulation ${ }^{143}$ might mean for future participation in pricing decisions among the stakeholders operating through the Steering Group.

Concerns from a second direction as to the management of the intellectual property rights (IPRs) involved in the NSAI came from interested parties, not strictly stakeholders, who were keen to submit their views. Since stakeholder input ${ }^{144}$ had been obtained prior to publication of the Prospectus it was not strictly a consultation document. However, its publication was bound to lead to a response. The AGI, for example, while commenting ${ }^{145}$ on the detail of the proposed content and structure of the database, ${ }^{146}$ also observed that the NSAI, as a "definitive" national information infrastructure would, inevitably, become a national monopoly and the governance of this and the mandate it operated by would have to be clear from the start. AGI argued that it was vital to settle the IPR issue on the use of address data. It called upon ODPM to obtain a statement from PostComm, ${ }^{147}$ as the regulating authority for the PAF (a major data contributor to the NSAI), to

\footnotetext{
${ }^{139}$ Ibid., pp. 13-14.

${ }^{140}$ The only concrete statement as to actual amounts in the Prospectus declared that ODPM would make £2.3 million available to Surrey County Council "to enable the transfer of the NLPG database to the NSAI and to help facilitate local government's transition from one system to the other."

${ }^{141}$ OS, Update on the National Spatial Address Infrastructure, 11 August 2005.

${ }^{142}$ Crown copyright is defined by s. 163 of the Copyright Designs and Patents Act 1988 as covering those works

"...made by Her majesty or by an officer or servant of the Crown in the course of his duties". This definition includes databases made in this way as well as works commissioned by government departments from the private sector.

${ }^{143}$ For further analysis of Crown copyright regulation and policy development see: S. Saxby, 'Crown copyright regulation - Is the debate still alive’, 13 International Journal of Law and Information Technology No. 3, Autumn 2005, pp. 299-335.

${ }^{144}$ Op, cit., note 129 ante, para 8.1. Views were obtained from "central agencies and local authorities ...the emergency services, academia and commercial businesses.”

${ }^{145}$ H. Robert Mann, Director AGI, Response from the Association for Geographic Information on the Outline Prospectus for the National Spatial Address Infrastructure, (AGI, 30 June 2005).

${ }^{146}$ AGI was concerned that since the proposals appeared to centre upon Royal Mail postal addresses "many public buildings, residential or commercial multi-occupied properties, industrial premises, premises with PO box numbers, or campuses such as universities, hospitals or military establishments” may not be adequately represented within LLPGs.

${ }^{147}$ PostComm is the independent regulator for postal services in the UK. See further: www.postcomm.gov.uk/.
} 
explain how this would work. Basic address data would need to be provided at a "reasonable price" since "widespread criticism" existed of OS among users and potential users that "the current commercial prices of many products are excessive and restrict use."148 AGI attacked "suggestions" that NSAI data might cost users 50\% more than AddressPoint and called for the withdrawal of this suggestion. Otherwise, it said, there was a severe risk that the wider community would be priced out of the opportunity to acquire and use the data. AGI, while strongly supporting the principles and objectives for a NSAI, observed that past experience with such initiatives would require greater clarity over the "IPR issues, inter-agency co-operation, funding and technical specifications" to ensure the success of the project. As matters stood, it was not clear whether the NSAI was intended to be a "product, a service or a process". How it would be delivered also remained unclear. ${ }^{149}$

Another issue, not discussed at all in the Prospectus, was raised it its comment by EURIM - the all party Parliamentary industry group. ${ }^{150}$ It was currently working on questions designed to "clarify objectives" relating to the Government's ID Card programme and drew a link between the NSAI and the proposed National ID Database to be established under the Identity Cards Bill, ${ }^{151}$ presently before Parliament. The current or previous address of an individual played a "vital role" in the assessment of personal identity attributes. There was evidence of "significant anomalies" in the data held across the various databases that were being groomed for inclusion in the NSAI. Such problems would need to be examined so that the findings could be dealt with by their custodians. In short, the EURIM paper asks questions about the purpose of the NSAI, how it will be used and what safeguards will be introduced. EURIM commented that a lack of time prevented a more detailed response.

What this shows is that further discussion with the Information Commissioner's Office must take place before the NSAI can become operational to ensure compliance with the Data Protection Act 1998. The data protection implications of what is being proposed must be considered to establish whether any restrictions or conditions need to be put in place as to the range of possible uses of NSAI data by both the public and private sector. The Government will have to assess these issues once the Information Commissioner has reported.

Official comment on the current position has come from the Local eGovernment Minister in the ODPM, Jim Fitzpatrick MP who said, on 11 August 2005:

"I am disappointed that Ordnance Survey and IDeA are unable to proceed as planned with the creation of the National Spatial Address Infrastructure. Given that addressing is a critical piece of infrastructure I hope the parties will continue to consider options to meet the objectives set out in the prospectus we published in May. ODPM continues to offer its active support in achieving this." 152

Speaking again at the AGI Conference and Exhibition in November the Minister reiterated that he was:

\footnotetext{
"as determined as ever that we will achieve the goal of a definitive national address infrastructure and will work with colleagues to achieve this... It is no secret that the goal of a defining address dataset has been just within our reach on a number of occasions over the past few years. The benefits that a definitive dataset can bring are eloquently stated in journals, at conferences such as this and in day to day dialogue between
}

\footnotetext{
148 Op. cit., note 145 ante, p. 4 ..

149 Op.cit., note 145 ante, p.2.

${ }^{150}$ EURIM Personal Identity Group, Response to the NSAI Prospectus, 29 June 2005. EURIM is the European Information Market Group

${ }^{151}$ Identity Cards Bill available at: www.publications.parliament.uk/pa/cm200506/cmbills/009/2006009.pdf.

152 Op. cit., note 141 ante.
} 
stakeholders in the industry....The Government wants to see effective provision of the most appropriate geographic information... Users will, quite rightly, become more and more demanding. We must meet their expectations.”"153

However, reporting on its achievements in 2005 an AGI review commented:

\begin{abstract}
"Progress on the NSAI seems very slow. At the time of writing, AGI has arranged a meeting at IDeA to seek clarification on NLPG activity under the new Local Authority Mapping Services Agreement. ODPM has declined a request to meet with AGI, but Ordnance Survey has invited the Address Geography Special Interest Group of AGI (AGSIG) to have a special session on its new Address Layer product plans.” 154
\end{abstract}

Given the present position in which the talks remain deadlocked, one GI specialist, Dr. Robert Barr of the University of Manchester has said that the continuing failure to create the NSAI is "the most serious breakdown of the last five years" in government IT in the UK. ${ }^{155}$

\title{
4. The way ahead
}

The culmination of the analysis thus far suggests that three basic questions need to be considered: what is the UK Government's strategy for GI; what is the role of that strategy in the enhancement of eGovernment objectives; and what actions might be considered to further encourage more interplay between these two elements of policy? In general terms the UK has done well in recognising, at an early stage, the value of geo-spatial information to government, business and the public at large. It was fortunate to have created in OS, more than two centuries ago, an organisation that could both attract and mould the technical expertise that was fundamental to help craft the components of a national spatial infrastructure. Such efforts have added value to a digital resource ${ }^{156}$ that now lies ready to be utilised in promoting, inter alia, the eGovernment agenda improved services, more efficient and informed government and greater synergy in crafting policies involving multi-departmental input.

It is submitted that there are at least three areas of current policy that the Government needs to look at if these objectives are to be fulfilled. First of all, it needs to define its GI strategy, articulate the value of GI to eGovernment programmes and develop best practice that can be widely disseminated. It needs to take a broad look at the current distribution of responsibility for the different strands of GI strategy and identify ways to manage its complexity. Second, it needs to relate all this to funding and pricing issues. This is particularly so in considering how to apply such fiscal policies to the supply of "public interest" infrastructure and services, as opposed to those that ought perhaps to be developed on purely commercial lines. Are the current arrangements governing Trading Fund operators such as OS, for example, as well as rules on Crown copyright, as presently applied, going to induce the progress that the Government desires? Finally, it needs to relate its policies to the broader context of EU developments and to data protection and freedom of information obligations.

\footnotetext{
${ }^{153}$ Communities, citizens and co-operation - Speech by Jim Fitzpatrick MP to the Association for Geographic Information (AGI) Conference Places, people and partnerships, Chelsea Football Club, 8 November 2005: http://www.odpm.gov.uk/index.asp?id=1161492

${ }^{154}$ Activities and achievements - report to members 2005 at www.agi.org.uk/SITE/UPLOAD/DOCUMENT/Reports/Activities_Achievements2005.pdf

${ }^{155}$ IDABC eGovernment News 27 September 2005 - UK government cancels plans for National Spatial Address Infrastructure.

${ }^{156}$ Expertise such as that required to develop the DNF for example.
} 


\title{
4.1 Developing an 'eGov' GI strategy for England, Scotland and Wales
}

\begin{abstract}
A working group of $\mathrm{AGI}^{157}$, the organisation representing the interests of the UK GI industry, commented, in April 2004, that the purpose of a domestic GI strategy was:

"to make possible the ability to access and share up-to-date, accurate and seamless geographic information to enable enhanced citizen engagement, public service delivery, policy development and private enterprise.”"158
\end{abstract}

GI had become "specifically associated with the processes and systems (GIS) for integrating and analysing spatial data." The latter could offer greater geographic knowledge than any single dataset could provide, but the problem remained that "for the most part" such material still existed in forms that restricted their use to the organisations which owned them. Both legal and cross-referencing "barriers" were present, frustrating data exchange and the integration of information. Tackling such impediments was important, since a GI strategy lay "at the heart of the concept of modernising government" and deserved the "highest level of government commitment and governance". Data needed to be collected only once, then managed and maintained to consistent quality standards. If this was achieved then data could be used and shared by government in a "multitude of citizenfocused applications” within a "fully connected” electronic service delivery environment. ${ }^{159}$

This aspiration was also supported by IGGI ${ }^{160}$ - the international forum for departments and agencies to consider and develop common approaches to GI and facilitate its use. From its point of view, however, effective use of GI within an organisation required "more than the deployment of GIS technology." ${ }^{161}$ Rather, it needed "establishment of an overall spatial data infrastructure" that would deal with the "broad policy, organisational, technical and financial arrangements needed to support ready access to geographical information.” The use of GI and GIS within government was complex, requiring "significant investment in terms of data, systems and staff resources" as well as the integration of a variety of datasets within a common GI framework. ${ }^{162}$

In assessing these policy statements against the reality of government 'strategy' for GI, the truth is that clarity as to what that strategy might be is hard to discern. One can start with the basic aspiration, which is implicit in its pronouncements, that the development of public services would benefit from eGovernment initiatives and, in particular, that public sector information (PSI) might be more effectively exploited if a GI dimension was included. ${ }^{163}$ But, thereafter, the search for a strategy fragments into a description of the initiatives that either develop and supply the infrastructure for the use of GI within government, such as the DNF and NIMSA or utilise it, along with other forms of data, in the process of policy development or service delivery viz., Directgov, ${ }^{164}$ Government Gateway, ${ }^{165}$ Government Connect, ${ }^{166} \mathrm{eGIF}^{167}, \mathrm{GSi}^{168}$, and with metadata, - most recently the GIgateway, ${ }^{169}$ utilising the 'GI friendly' UK GEMINI standard. ${ }^{170}$

\footnotetext{
157 The group comprised representatives from central and local government and from the private sector and was established following a seminar held by AGI, Local Government Special Interest Group (LGSIG), in collaboration with the Intra-Governmental Group on Geographic Information (IGGI) and IDeA in 2003.

${ }^{158}$ A Geographic Information Strategy for England - Consultation document (AGI Working Group, London, April 2004) p.6.

159 Ibid., p. 9.

160 See note 89 , ante.

${ }^{161}$ Departmental Geographical Information Strategies - Best Practice Guide, (IGGI, October 2002) para 2.3.

162 Ibid., para 3.1.

163 See note 36 et seq., ante.

164 See note 28 , ante.

165 See notes 51 \& 68, ante.
} 
Having developed these arguments it is, nevertheless, a fair question to ask whether the creation of yet another 'strategy', i.e. one for GI, is the appropriate response to tackling these problems? It is submitted that whether 'strategy' is the correct term or not to describe what must occur, there does need to be improved co-ordination in the management of GI-related matters. There also needs to be better understanding, across the whole public sector, of what GI can contribute towards better government and, particularly, fulfilment of eGovernment objectives. For that reason the need for a strategy can be supported. Strategic management of the complexities involved in crossdepartmental responsibility for different strands of GI policy needs to occur, not to mention integration of the technical and standards issues that the whole field of GI induces. To quote OS:

"in the UK we are starting to realise the power of geography in assisting decision-making at the strategic policy level, in improving operational performance, and in communication with the citizen. “171

If OS is correct in this assumption then, for the reasons just advanced, a case has been made for the Government to take a fresh look at how to bring some order into GI policy management. In broad terms it could not be said that the Government is necessarily failing to act or to recognise the strategic importance of GI and GIS to its ongoing activities. The difficulty lies, however, in its management of the diverse policy elements involved. It would seem that, at least until now, no single entity has the mandate, supported by the necessary authority and resources, to co-ordinate and advance the infusion of GI resources into government. Remits may exist, with specific responsibility for particular inputs towards development of either GI infrastructure or content, but cohesion in terms of the fit of these developments to the bigger GI picture appears to be dependent on no more than circumstance or aspiration. A brief map of the current template will demonstrate this complexity in the diffusion of responsibility.

To begin with the ODPM has Ministerial responsibility for OS. OS is a government department responsible for “official, definitive surveying and topographical mapping of Great Britain.” In relation to GI, OS is also responsible for "maintaining consistent national coverage of other nationally important geospatial datasets." 172 The fiscal disciplines of Trading Fund status apply to OS and add complexity to process by which it supports the dual role of delivering public interest mapping services, while at the same time fulfilling its commercial responsibilities as dictated by its status. By a Treasury Minute of 2004, OS is required by ODPM (from April 2004 - April 2007) to achieve an average 5.5\% surplus on ordinary activities before interest payments and dividends. ${ }^{173}$ ODPM also has a shareholder interest in OS and is entitled to a dividend payment each year to "offset capital employed in the business." ${ }^{174}$ Whereas OS has taken the lead, with others, in initiating the framework for the DNF, ODPM has Ministerial responsibility for NIMSA, with oversight "of the operation of the agreement and the activities covered" in the hands of the NRG. ${ }^{175}$ Local government exploitation and development of GI as evidenced, for example, through the $M S A^{176}$ and Government Connect, ${ }^{177}$ brings in ODPM again through its Minister for Local

\footnotetext{
166 See note 54 ante.

167 See notes 50, 65, 105 \& 131, ante.

168 See note 56 , ante.

169 See notes 101-107, \& 119-121, ante.

${ }^{170}$ See notes 103-107, ante.

${ }^{171}$ Op. cit., note 17 , ante p. 9.

${ }^{172}$ Framework Document- Ordnance Survey Executive Agency, (OS, July 2004).

${ }^{173}$ Treasury Minute dated 15 January 2004 pursuant to s. 4(1) Government Trading Funds Act 1973.

${ }^{174}$ Office of the Deputy Prime Minister Annual Report 2005, Cm6526 (The Stationery Office, June 2005).

${ }^{175}$ Op. cit., note 116 , ante.

${ }^{176}$ See note 87 , ante.

177 See note 54 , ante.
} 
Government, as well as IDeA - the company wholly owned by the Local Government Association (LGA). IDeA's remit, inter alia, is to connect "ideas and expertise, both within the sector and beyond, to cross fertilise solutions and accelerate progress." ${ }^{178}$ IDeA, as the negotiating organisation for the transfer of NLPG to OS, also participated in the failed talks on the development of the NSAI that reached deadlock with OS in August 2005. ${ }^{179}$

Beyond ODPM, other significant remits, with varying degrees in the specificity of their application to GI policy, are those that reside in the new organisations within the Cabinet Office - the eGU and OPSI. eGU's contribution ${ }^{180}$ is to "work with departments to achieve efficiency savings and improve access to public services through electronic delivery". Through its Electronic Delivery Team $^{181}$ it has steered the development of the Government Gateway and is responsible for connectivity standards such as eGIF, ${ }^{182}$ as well as metadata standards such as eGMS. On connectivity, the eGU has established an eGIF Accreditation Authority to ensure that both public sector and external suppliers deliver 'eGIF compliant' solutions. Day-to-day operation of these services is run by the National Computing Centre (NCC). ${ }^{183}$ More recently, through collaboration with AGI, ${ }^{184}$ eGU has also brought forward UK GEMINI into the eGMS. Meanwhile, AGI, as the national GI association for the UK, is also contracted to manage the GIgateway metadata service funded by NIMSA and is a regular contributor to many policy debates on GI. eGU also runs operational teams to oversee Directgov - the Government's 'flagship' online public information service and the Knowledge Network, which builds and manages secure websites and shared databases across government. Following a review in 2005, the "delivery aspects" of this service are to be outsourced. A UK GovTalk website is also maintained offering advice and consultation on eGU policy guidelines.

OPSI, ${ }^{185}$ formerly known as HMSO, was renamed in 2005 to recognise its expanding role at the heart of government information policy. It has responsibility to deliver access and encourage re-use of PSI and, through its e-Services Team, to ensure that "an evolving e-strategy" lies at the core of its operations. ${ }^{186}$ It also receives advice from an independent Advisory Panel on Public Sector Information (APPSI) that offers an independent strategic view on re-use of PSI within the wider economy. To complete the picture, the Cabinet Office Strategy Unit ${ }^{187}$ deals with policy-making at the strategic level, including the digital agenda. ${ }^{188}$ Its Policy Hub also offers a "wide range of information and guidance on policymaking and delivery across government.",189

Still within the Government, but outside the Cabinet Office, there is the OGc ${ }^{190}$ - an independent office of HM Treasury. This was set up in 2000 to work with departments to achieve efficiency

\footnotetext{
${ }^{178}$ See further: www.idea-knowledge.gov.uk/. Other duties include "focusing on best practice and forward thinking”; securing the delivery of a "flexible range of tools and services" to local communities; and "carrying risk on behalf of local government by innovating and incubating new joined up but locally delivered initiatives.”

179 See section 3.5 , ante.

180 See notes 51-53 ante.

181 See note 53, ante.

182 eGIF and $e G M S$ are currently under review within eGU. Results are expected to be published in 2006.

${ }^{183}$ NCC is based in Manchester. Metadata and UKGovTalk are co-located at NCC.

${ }^{184}$ See notes $90-92$, ante.

${ }^{185}$ See note 58, ante.

186 See further: www.opsi.gov.uk.

187 See further: www.strategy.gov.uk.

${ }^{188}$ See, for example, the Strategy Unit’s joint report with the DTI in March 2005 on UK digital strategy, op.cit., note 2, ante. This sets out the role that information and communication technology (ICT) will have on future prosperity and considers also the "digital divide” which currently "excludes some groups from benefiting from access to the Internet."

${ }^{189}$ See further: www.cabinetoffice.gov.uk.

190 See note 57 , ante.
} 
savings in programme and project delivery, as well as value for money returns in procurement. In pursuing its responsibilities OGc has utilised GI resources in the pursuit of its goals. It is the OGc, for example, that developed ePIMS, ${ }^{191}$ following the Modernising Government White Paper; ${ }^{192}$ a database offering property information management services using digital maps. This has enabled departments to manage their own estates and property transactions more effectively. Strategic understanding of how OGc came to recognise the benefits of establishing this particular resource is needed. This might well reveal other possibilities for utilisation of GI tools, within the public sector, that have not thus far been assessed.

In weighing up all this, it seems clear that three sorts of GI-related elements can be identified within government, and within its dealings with non-governmental organisations (NGOs) and the private sector. First, there are those that have responsibility, whether motivated by the public interest or commercial factors, for developing GI infrastructure. This includes both the use of technical expertise necessary, for example, to develop the DNF and other infrastructure, as well as the investigation of the standards and models to be adopted in bringing this into existence. Second, there are the GI content providers, which may in some instances overlap with those concerned with infrastructure, whose focus will be on building useable content that can be accessed efficiently across government. Within this group will be the 'sleeping partners' - department and units that are unaware of the GI datasets that they may hold or could conceivably develop and put into use. Thirdly, there are the potential users of GI resources across government which, again, may or may not have understood the connections between the discharge of their responsibilities and the benefits to be gained by integrating GI resources into those activities.

At present, what is lacking is a structure to mould and galvanise GI infrastructure developers, content producers and potential users within a defined strategy and to provide the necessary information and support to enable GI resources to be identified and applied where they might best be deployed across government. If it is accepted that GI can introduce efficiencies into public sector service provision and contribute significantly to eGovernment objectives, and if it is also accepted that a lack of strategic support exists to co-ordinate public sector exploitation of GI and the products and services it underpins, then the time has come to establish the means to tackle the issue. The announcement in 2005 by the ODPM that a Geographic Information Panel (GI Panel) has been set up may, in fact, represent a move in the desired direction. If so this represents a very significant development. Announcing the formation of the Panel the ODPM said:

"The Panel will focus on medium to long term issues and will encourage more effective, extensive and systematic use of geographic information. The GI Panel will provide short reports to Ministers. This high level advice will complement the advice provided to the ODPM Minister with responsibility for Ordnance Survey by the Director General and Chief Executive of the Ordnance Survey. “193

At present the GI Panel comprises representatives from departments and agencies, local government and industries, such as insurance, with an interest in GI. AGI has representation but argues that the interests of some "key constituencies" in the GI field need to be accommodated too viz., the "academic community, utility companies and the GI software and services industry". ${ }^{194}$ In AGI's view the GI Panel needs to prioritise the development of a "GI strategy for the whole of the

\footnotetext{
191 Ibid.

192 Op. cit., note 39, ante.

193 Informing, Influencing, Acting (AGI statement at www.agi.org.uk).

${ }^{194}$ Ibid. AGI declared that it was pleased to note that the ODPM had stated that GI Panel membership would be "reviewed regularly."
} 
UK.”195 The ODPM website ${ }^{196}$ offers some information as to the aims and terms of reference of the GI Panel, but until minutes of meetings are posted it will not be clear what this panel of experts can achieve in terms of working towards a UK GI strategy. Only when further information becomes available as to the range and scope of its proposed agenda and action points, will it be possible to judge whether this really does amount to a new understanding, within the Cabinet Office and the Government, of what must be done to develop management structures for the development and use of GI resources in this country.

\subsection{GI funding and pricing policy}

Important elements in the equation for building a successful GI management and integration model within government are the funding and pricing regimes applied to the development and the exploitation of the products and services that emerge. The point is well made that, unless 'ring fenced' for the specific purpose, funding a model for development and implementation of GI strategy, even if taken up on terms recommended by some form of strategic authority, will still to some extent be dependent upon fiduciary decisions taken by the departments and agencies themselves. This is inevitable because the potential public sector application of GI to activities where it can conceivably contribute efficiencies, pervade the whole of government. As such, investment in GI resources designed to produce efficiency gains in the medium to long term, are going to face budgetary pressures dictated by the need to undertake the activities themselves rather than spending to improve their means of delivery. Moreover, gains that might accrue from layering GI techniques into the fabric of government may not have been recognised or understood. Investment in GI resources, designed to offer cross-departmental applications, may inevitably produce a complicated set of budgetary negotiations among participants viz., departments, agencies, Trading Fund operators, NGOs or private sector investors, of a similar kind to those that led to the recent failure to move forward on financing for the NSAI.

Added to this are the pricing policies, developed within government, to deal with access to and reuse of PSI which now increasingly includes GI. ${ }^{197}$ Whilst the Government has always recognised the value of its information resource as a tool for its own use, it has now also begun to appreciate the considerable economic importance of the potential information market that exists in the re-use of that information in development of value-added products and services. Since the Cross Cutting Review of the Knowledge Economy by HM Treasury in $2000^{198}$ it has developed a model designed to promote the re-use of this resource in the wider economy while, at the same time, developing pricing policies that are intended to achieve some cost recovery or even a commercial return and recognise other competing interests. ${ }^{199}$

Until Crown copyright policy was drawn into the broader eGovernment agenda, the Government had, through HMSO, operated a somewhat fluid and, at times, opaque regime of regulation of the IPRs. Under this approach, securing the integrity of Crown copyright resources and obtaining revenues from licensing private sector re-use of its information resources, appeared to be of greater priority than the development of arrangements that would ensure that the wider economic benefits of access and re-use of PSI were accounted for. Commenting on this, the Review stated:

\footnotetext{
${ }^{195}$ AGI argues that such a strategy would build on the strategies "already in place or in the course of creation in Wales, Scotland and Northern Ireland.”

${ }^{196}$ See: $w w w . o d p m . g o v . u k / i n d e x . a s p ? i d=1144584$.

197 The user pays model has been widely adopted across all colours of government.

${ }^{198}$ Cross Cutting Review of the Knowledge Economy Review of Government Information - Final Report (HM Treasury, December 2000).

${ }^{199}$ For a full discussion of this issue see S Saxby, op. cit. note 143, ante.
} 


\begin{abstract}
"The current policy of average cost pricing creates a significant barrier to the re-use of information because it requires parts of government, where this is not a core business, to make assessments and attributions of relevant costs and negotiate individual contracts in an area in which many departments and agencies are illplaced to operate. Marginal cost pricing would remove this burden from both the department concerned and the private sector." 200
\end{abstract}

Although HM Treasury concluded that more empirical work was needed on the economics of information pricing it proceeded to encourage, in the main, a marginal cost policy across government for access to its information resources. In simple terms this meant charging no more than the production cost of supply, except where this was likely to produce fiscal burdens elsewhere in the economy, including for the taxpayer. This might occur, for example, where specific datasets or information resources had been particularly expensive to collect or where government had gone beyond its own needs in collecting data. Whilst the expectation would be that dissemination between departments would be managed under such a pricing model, different arrangements needed to be offered to Trading Fund operators, whose statutory obligations required some return on their activities. Each Trading Fund was different and pricing arrangements needed to reflect this. However, to ensure that "dominant players" did not exploit their position to the detriment of others, HMSO introduced an Information Fair Trader Scheme in 2002 to encourage Trading Funds, in particular, to declare their pricing policies. ${ }^{201}$ It remains to be seen whether any competition issues will arise within this pricing strategy. ${ }^{202}$

The spatial dimension of GI introduces potentially more difficult questions for pricing policy than would normally be the case for conventional forms of PSI. Because of its functionality, GI is a "high value commodity". This is due to the products and services that can be built around it. The very high cost involved in its creation and development adds a new dimension to the policies already in place for development of other 'non GI', 'value added' information resources. There is a dilemma for government here, since the potential contribution of GI, GI tools and their associated technologies towards many government activities, is going to play an important role in achieving eGovernment strategy. Since that strategy is designed to utilise ICT to improve public services and enhance the democratic process, these goals must be taken into account when developing the economic arguments for investment in, and pricing access to, the GI resource.

A department such as OS, with its Trading Fund obligations strictly defined, is faced with some difficult decisions here too, as is ODPM and the Deputy Prime Minister, in terms of Ministerial oversight. On the one hand OS is strictly tied, until 2007, to a 5.5\% average return on activities and must price its products and services accordingly. Yet it is a major player in the development and delivery of GI infrastructure, products and services (GIIPS) and offers high levels of technical support and advice on spatial data to the Government. It also participates in the development of "national interest mapping services", as evidenced by its pivotal role in fulfilling NIMSA obligations. From the Government's point of view such expertise, held within OS and elsewhere, needs to be secured to ensure that any model for GI in terms of infrastructure, content and use can be identified, funded and delivered in a sustainable, cost effective and managed environment. To illustrate the point, OS and the Government have, somehow, to find a transparent means to

\footnotetext{
${ }^{200}$ Ibid., para 1.15. This point is discussed in Max Craglia, Robin Smith and Saulius Eds, Geographic Information Policies in Europe: Technical Report D.2.7.2(b) (GINIE: Geographic Information in Europe, IST-2000-29493, February 2003) pp. 28-31.

201 The Scheme requires "strict adherence to an open and transparent trading regime consistent with the Competition Act 1998." Signatories must also commit themselves to other principles set out in Information Fair Trader Scheme (Cabinet Office, HMSO). All Trading Fund operators wishing to undertake licensing responsibility under delegation from HMSO (as it then was) must have joined the Scheme by March 2005.

202 See notes 241-246 post.
} 
underpin core GI development; identify the level of "public interest" investment in this; enable OS to trade or deliver access to the GIIPS that it has helped develop mostly from revenue earned via various sectors but with some taxpayers' money - without infringing UK competition law, EU Single Market rules, ${ }^{203}$ or its Trading Fund obligations; secure pricing arrangements ${ }^{204}$ for use of GIIPS across the rest of government that will encourage departments to utilise and build on the contribution that GIIPS can offer in the fulfilment of eGovernment aspirations; and stimulate the creation of a strong private sector interest in GIIPS so that UK business can utilise it, both for its own benefit and that of the UK national economy.

The problem has been articulated thus:

\begin{abstract}
"At the core of such challenges lies the tension between the potential economic value of public sector information in general, and GI in particular, and its social and policy value. Therefore, the potential social and policy value that accrue from maximising the dissemination of geographic information needs to be balanced with the competing pressures from Treasury Departments to maximise revenue for government agencies, and from other departments, such as that for Trade and Industry, in order to support the development of a vibrant private sector in the value-adding information business.”205
\end{abstract}

It is going to be totally unrealistic to suggest that a strategic body, such as the GI Panel, should be permitted to usurp, in any way, the firm control that HM Treasury desires over investment arrangements for GI activities. However, it would be equally unrealistic to expect that HM Treasury is capable of making fiscal decisions, based on all the considerations just outlined, without a strategic appreciation of what GI can contribute to fulfilment of government objectives. Nevertheless, a partnership is possible between the GI Panel and HM Treasury to help develop a deeper understanding of what needs to be done. Once known, this could be measured against the Government's 'flagship' manifesto and policy objectives, such as those for eGovernment. In addition to the discovery of best practice for more widespread adoption, a strategic review is also likely to uncover inconsistencies, flaws and weaknesses in the GI policies currently operating within government. This is inevitable for what is still a new and potentially versatile resource that has yet to be fully exploited within the public sector. If this data can be identified, the Government stands a better chance of targeting where specific funding allocations for development of GIIPS will make a difference. However, it is not just a question of funding. Persuading organisations to respond and change their practices is just as challenging as well as the issue of maintenance, which tends to be overlooked. Perhaps better results are likely if a parallel GI strategy group, within HM Treasury, is also established to evaluate and respond to input from the GI Panel on resource issues. This will be particularly helpful in evaluating potential GI efficiency gains when assessing departmental bids during the annual spending review.

\title{
4.3 Beyond UK GI - the broader policy implications
}

The third set of considerations that must be taken into account in developing a GI strategy for the UK are those dictated by regional developments of which the UK is a part, particularly those within the European Union (EU). In 2001, for example, the Infrastructure for Spatial Information in

\footnotetext{
${ }^{203}$ Care must be taken to ensure that GIIPS subsidised with public money and marketed by Trading Funds under Crown copyright provision and/or Trading Fund legislative requirements, do not place private sector competitors at a disadvantage in the market. Given the functional nature of GI technologies patenting issues are also likely to arise in this debate.

${ }^{204}$ Where taxpayers' money has already been used to create the product, an argument can be made that the tax payer should not have to pay a second time through charges levied, for example, at commercial rates by Trading Funds to departmental purchasers, for access to that product

${ }^{205}$ Op. cit., note 200, ante p. 33.
} 
Europe (INSPIRE) initiative was launched by the EU with the aim of making available "relevant, harmonised and quality geographic information for the purpose of formulation, implementation, monitoring and evaluation of Community policy making." ${ }^{206}$ Initially INSPIRE focused upon environmental policy, but its remit is now "open for future extension to other sectors such as agriculture, transport and energy." 207 In July 2004, the European Commission published a Proposal for a Framework Directive 208 for establishing an infrastructure for spatial information in the Community. The Recitals to the proposed Directive gave details of the rationale:

\begin{abstract}
"The problems regarding the availability, quality, organisation and accessibility of spatial information are common to a large number of policy and information themes and are experienced across the various levels of public authority. Solving these problems requires measures that address exchange, sharing, access and use of interoperable spatial data and spatial data services from across different sectors. An infrastructure for spatial information in the Community should therefore be established.”209
\end{abstract}

The Proposal suggested that infrastructure for spatial information should be based on existing schemes developed by Member States. ${ }^{210}$ The aim should be to establish "appropriate levels" for the storage, maintenance and distribution of spatial information, while ensuring that spatial data from different sources across the Community be shared, as far as possible, among different users and applications. Spatial data collected at one level of public authority should be accessible between "all levels of public authorities" under conditions that did not inhibit their extensive use. The Commission further called on Member States to introduce arrangements to ensure that it was easy to "discover available spatial data, to evaluate their fitness for purpose and to know the conditions applicable to their use." 211

To date, the UK Government's response has been supportive of the aspirations of INSPIRE and the importance that the Commission attaches to GI as a means of underpinning development and delivery of EC policies. ${ }^{212}$ It has secured representation within the Expert group and taskforces examining the proposal and, in line with common procedures for achieving agreement on European proposals, the UK lead department (DEFRA) is conducting the Regulatory Impact Assessment and has consulted widely including the AGI as the "recognised national organisation representing the UK geographic information community,". ${ }^{213}$

In February 2005, following reference to it by the Council, the European Economic and Social Committee of the EU offered its opinion on the proposed directive. ${ }^{214}$ It endorsed the establishment of INSPIRE, noting that the infrastructure would "co-ordinate and make interoperable and accessible all spatial data collected at the national level”. ${ }^{215}$ This would help Member States to

\footnotetext{
${ }^{206}$ University of Sheffield - USFD, Geographic Information Policies in Europe: Recommendations for Action D.2.7.2(a) (GINIE: Geographic Information Network in Europe, IST-2000-29493) p. 5.

${ }^{207}$ Proposal for a Directive of the European Parliament and of the Council establishing an infrastructure for spatial information in the Community (INSPIRE) (COM(2004)516 final, Brussels, 23 July 2004) p. 3.

${ }^{208}$ A "Framework Directive" allows broad scope for subsidiarity (devolution of control to Member States as to the means of implementation) so that the provisions can be tailored to reflect the diversity of the Member States and the regions they inhabit.

${ }^{209}$ Ibid., Recital 3.

${ }^{210}$ Ibid., Recital 4.

${ }^{211}$ Ibid., Recital 5.

${ }^{212}$ Op. cit., note 100 ante, p.11. This included Department of Environment, Food and Rural Affairs (DEFRA) and ODPM as joint leads.

213 Ibid.

${ }^{214}$ Opinion of the European Economic and Social Committee on the Proposal for a Directive of the European Parliament and of the Council establishing an infrastructure for spatial information in the Community (INSPIRE) COM(2004) 516 final - 2004/0175 (COD)) 2005/C 221/7).

${ }^{215}$ Ibid., para 1.1.
} 
document "environment related decisions and their follow-up" on a more scientific basis, as well as reports connected with other directives. Moreover, the initiative would improve "efficiency in the use of data by the administrations and services concerned and in the use of data by public and private operators in various forms, including value added services (specialist maps or databases etc)." ${ }^{216}$ In June 2005, member states reached political agreement on a Common Position taking into account its earlier (April) position. ${ }^{217}$ This now goes forward for a second reading.

It is clear that the UK needs to retain awareness of, and participation in, the implementation of EU initiatives regarding development of a European Spatial Data Infrastructure (ESDI). The same benefits that potentially apply to the exploitation of GI in the UK can be argued for across the EU. The INSPIRE initiative addresses the broad issues - "common reference data and metadata, architecture and standards, legal aspects and data policy, funding and implementation structures, and impact analysis" that will be necessary to bring the ESDI into existence and the main participants together. ${ }^{218}$ The EU has already legislated on related aspects of data dissemination policy through its revised Directive on access to environmental information ${ }^{219}$ and the Directive on re-use of PSI. ${ }^{220}$ Development of an ESDI is the logical next step for the EU as it seeks to integrate GI within its eGovernment and information society agendas that have steadily evolved since the 1990's. ${ }^{221}$ Successive eEurope Action Plans ${ }^{222}$ have incorporated proposals for improving online access to public information. These envisage greater private sector participation in the development of value-added services as new data sets become available. The EU agenda for eGovernment calls for participation among both Member States and the Commission in developing online services and applications. $^{223}$ The current proposals for an ESDI are perceived as an opportunity for the GI community to act on their contention that the benefits of GI to eGovernment are "not being picked up by the various eGovernment observatories at the global, European or national levels." ${ }^{224}$ This task will be ongoing as INSPIRE has been described as more of a "process than .... fixed legislative

\footnotetext{
${ }^{216}$ Ibid., para 1.2 .

217 Texts adopted by Parliament - Infrastructure for spatial information in the Community (INSPIRE) (Tuesday 7 June, 2005, Strasbourg).

${ }^{218}$ University of Sheffield - USFD, Editor Martin Klopfer, New Issues for the GI Research and Technology Development Agenda D 4.3.1 (GINIE: Geographic Information Network in Europe, IST-2000-29493, October 2003) p. 13.

${ }^{219}$ European Directive 2003/4/EC of the European Parliament and of the Council of 28 January 2003 on public access to environmental information and repealing Council Directive 90/313/EEC, (OJ L 41/26 14.2.2003).

${ }^{220}$ Op. cit., note 61,ante.. See also the policy discussion in eEurope 2002: Creating a EU Framework for the exploitation of Public Sector Information (COM (2001) 607 Final).

${ }^{221}$ See for example the White Paper on Growth, competitiveness and employment: The challenges and the way forward in the $21^{\text {st }}$ century (COM (93) 700 final, 5 December 1993) which outlined an action plan for development of an information network within Europe. See also Europe's way to the information society: an action plan, (COM (94) 347 Final.

${ }^{222}$ See the Government Online action line as proposed in eEurope: an Information Society for all (COM (1999) 687 and eEurope 2002: an Information Society for all: Action Plan prepared by the Council and the European Commission for the Feira European Council, (COM (2000) 323. A follow up Action Plan was adopted in 2002 which called for modern public services, including eGovernment by 2005 viz., eEurope 2005: an information society for all: an action plan to be presented in view of the Sevilla European Council, June 2002 (COM(2002)263 final, 28 May 2002).

${ }^{223}$ See: Communication from the Commission to the Council, the European Parliament, the European Economic and Social Committee and the Committee of the Regions: The Role of eGovernment for Europe's future, (COM (2003) 567 final).

${ }^{224}$ University of Sheffield - USFD, Author Chris Corbin New Issues for the European GI strategy - eGovernment, D.2.9.2 (GINIE: Geographic Information Network in Europe IST-2000-29493, October 2003) p. 9.
} 
instrument" since the work involved in developing requirements, standards and specifications will never be completed. ${ }^{225}$

A new set of questions for both INSPIRE and the GI community now lie ahead in working out its contribution to the Commission's new strategic framework - i2010 - European Information Society 2010 (i2010). This emanates from the Spring 2005 Lisbon Strategy presented to the European Council which declared that it was "essential to build a fully inclusive information society, based on widespread use of information and communication technologies in public services, SMEs [small and medium sized enterprises] and households." ${ }^{226}$ i2010 aims to lay out the "broad policy orientations" for a "competitive digital economy" that emphasises ICT as a "driver of inclusion and quality of life.”227 It announces that a new Action Plan for eGovernment will be produced to include strategic orientations on "ICT enabled public services." 228 This is based on political consensus within the EU that ICT plays a "key role to improve quality, efficiency and accessibility of public services.",229

A significant amount of background work on the issues raised by GI for Europe has already been completed. Working groups and partners operating within the INSPIRE programme have been active in developing understanding of the policy aspects of ESDI, ${ }^{230}$ as well as formulating the technical specifications for implementing the resource. ${ }^{231}$ In addition, the Geographic Information Network in Europe (GINIE) project, ${ }^{232}$ funded by the Information Society Technology Programme of the EU between November 2001 and January 2004, has produced a volume of analysis concerning the potential wider use of GI in Europe. Close attention has been paid to the role of GI in "supporting European policies with a strong spatial impact (agriculture, regional policy, transport, and environment), eGovernment, the re-use of public sector information ... and INSPIRE.”233 GINIE concludes that an urgent need has been identified:

to "maximise the availability and effective of use of GI in Europe.” This is necessary for a wide range of purposes: "good governance, economic and social development, informed public participation for eGovernment, citizen protection, security and environmental sustainability.” A European GI strategy would "influence and support high level decision makers in European and national governments and industry in order to realise this goal."234

\footnotetext{
${ }^{225}$ University of Sheffield - USFD, New Issues for the European GI strategy: the Infrastructure for Spatial Information in Europe (INSPIRE) initiative, D.2.9.1 (GINIE: Geographic Information Network in Europe, IST-200029493, October 2003) p. 4.

${ }^{226}$ Communication from the Commission to the Council, the European Parliament, the European Economic and Social Committee and the Committee of the Regions: i2010 - A European Information Society for growth and employment, (COM (2005) 229 Final, June 2005) p. 3.

227 Ibid.

${ }^{228}$ Ibid., p. 10.

${ }^{229}$ i2010 - A European Information society for growth and employment, (Memo/05/184, Brussels 1 June 2005) p. 6.

${ }^{230}$ See for example, Data Policy \& Legal Issues Position Paper (Data Policy and Legal Issues Working Group, INSPIRE - Infrastructure for Spatial Information in Europe, 4 October 2002).

${ }^{231}$ A variety of technical reports have been published dealing with implementing rules for monitoring and reporting, data and service sharing, spatial data specifications and harmonisation, metadata, and definitions of network services. The latest call for tender is to develop prototype components for the ESDI. See further: http://inspire.jrc.it/.

${ }^{232}$ Its partners are EUROGI - the European Umbrella Organisation for Geographic Information, the Open GIS Consortium - representing the GI industry, the Joint Research Centre of the European Commission and the University of Sheffield as co-ordinator.

${ }^{233}$ See further: www.ec-gis.org/ginie/home.html.

${ }^{234}$ University of Sheffield - USFD, Executive Summary - Towards a European GI Strategy: Lessons learnt from GINIE, Report D 2.11.1(a) (GINIE: Geographic Information Network in Europe, IST-2000-29493, January 2004$)$ p. 6. See also GINIE Final Report, D1.5.1 (IST-2000-29493, January 2004).
} 
So the question arises whether the European Commission's perception of what needs to be done to stimulate ESDI development in Europe offers a clearer understanding of the need to plan strategically for SDI than is suggested by the UK Government's current approach? In a review of GINIE, ${ }^{235}$ at the end of the programme, the principal consultant on spatial information policy remained sanguine on this point. This was despite what might have been anticipated, given the level of research into SDI already undertaken with financial backing from the EU. ${ }^{236}$ The consultant argued that, for him, the key message coming from GINIE was that:

\footnotetext{
"strong leadership and a balanced representation of stakeholders from government, industry, research and the European Commission are a condition sine qua non for instilling and implementing any strategy for Europe.” 237
}

Yet the reality was that it was "just this degree of highest level political support and strong leadership" that appeared to be "absent from pan-European SDI initiatives.” He pointed out that during the whole of 1994-1999 'GI2000' policy debate ${ }^{238}$ on ESDI development:
"despite the contributions of scores of experts, consultants, GI associations and interested national government bodies, there was never any truly high level interest in GI infrastructure, not even at the level of a single EC Director, let alone a Director General or Commissioner (despite what the public may have been led to believe!)."239

The consultant concluded by speculating whether it was now going to be enough simply to search for such political support. Although the "very ubiquity of GI", with its vast array of content, militated against any 'magic bullet' solution, perhaps the most hopeful solution for the future lay in the creation of an independent institution, some form of "pan-European GI council or similar" whose continuity in support of the principle of ESDI would never waver.

So, are there lessons to be learnt, both for the UK and EU, from the findings of such investigations? For the UK, it might consider whether it needs to engage more fully in the European debate, not only to help shape the direction it takes but to transfer that experience to domestic developments. Whether the present representation, held by the Government within the Expert Group of INSPIRE is going to be sufficient, remains to be seen? Above all, developing a degree of synergy between national and Community GI policies must be the goal if this can be attained.

In the meantime, one issue that may be of particular interest and, perhaps, concern for OPSI and HM Treasury is the suggestion made in one of the GINIE studies ${ }^{240}$ that the Commission should now look beyond the successes of its information policy, as represented by its PSI Directive, and consider a possible new directive on harmonisation of legal rules on data access and exchange of

\footnotetext{
${ }^{235}$ Roger Longhorn, Document Peer Review Report on First Review - Towards a European GI Strategy: The Lessons to be Learned from GINIE (D 2.11.1, October 2003) and Towards a European GI Strategy (D 2.11.2, October 2003) (GINIE: Geographic Information Network in Europe, IST-2000-29493, January 2004)

${ }^{236}$ GINIE involved more than 150 senior representatives from industry, research and government from 32 countries. ${ }^{237}$ Op. cit., note 235, ante p. 5.

${ }^{238}$ Although "never embodied directly into EU policy GI2000 “ this debate did much to stimulate support for development of GI strategy. Source: University of Sheffield - USFD, Editor Chris Corbin, A Compendium of European SDI Best Practice- Section 2 European Overview of SDI Initiatives, D.5.1.1 (GINIE: Geographic Information Network in Europe IST-2000-29493,, January 2004) p.1.

${ }^{239}$ Op. cit., note 235, ante p. 5.

${ }^{240}$ Op.cit., note 218, ante, p. 13.
} 
PSI. It seems that the lack of progress on this is mainly due to lack of Commission resources. ${ }^{241}$ If a proposal for such a directive was to be made it would focus the spotlight directly upon UK policy on Crown copyright. ${ }^{242}$ It might also raise competition and Single Market issues concerning the entire set of arrangements currently in place for pricing the information products and services generated by Trading Funds. It would also raise questions as to the arrangements that have operated up to now under NIMSA ${ }^{243}$ and similar types of agreement, where public investment in infrastructure lacking profit potential has occurred. ${ }^{244}$ For OS, in particular, such a proposal would have major implications for the continuity of present rules governing their trading operations. Could this mean a starving of investment in the database as occurred in the 1990's? ${ }^{245}$

\section{Conclusion}

There is a growing realisation that may now be beginning to spread beyond the expert community, that exploitation of GI within both central and local government can contribute new insights and techniques to the process of policy development through the spatial quality of the information resources it can provide. Understanding the true potential of this resource, as a contribution to good government, adds a further dimension to the evolution already underway in public sector exploitation of ICT. For more than three decades now, successive governments have been adapting their processes to harness digital technology. That process accelerated in the 1990's with the advance in network communications that is epitomised by the Internet. This has enabled the Government to improve its internal processes and to develop new forms of communication with the electorate. Out of this have emerged new policies too. At its root, the agenda for eGovernment is simply an attempt to define these aspirations and add some process and direction to their pursuit. However, it is important to keep up with the terminology. The year 2005 has witnessed a subtle shift in the terminology away from eGovernment towards the new agenda of 'transformation' in which the dimension of 'public value' must now be entered into the equation. ${ }^{246}$ This stresses the importance of understanding user needs in determining the shape of public service provision and particularly the need to bring hitherto excluded groups into participation in the information society.

Within the midst of such rapid change the Government is now faced with the task, first of assessing the merits, and then applying new spatial methodology to some of its operations, building new insights and efficiencies into the process. Discovering how to integrate such new technology into the support of existing activity never runs smoothly in any form of administration. This is particularly so if that technology produces a generic and versatile resource that can stimulate new practices and innovation. As GI capability unfolds, new avenues of enquiry for policy development and administration will also surface. In this way the new techniques, developed through GIS, can be gradually integrated within day-to-day activity.

\footnotetext{
${ }^{241}$ Op. cit., note 235, ante, p. 5. The paper suggests that there were other political considerations too in the fact that elections were taking place for a new European Parliament and new Commissioner appointments following the accession of new Member States into the EU.

${ }^{242}$ It was thought that such a proposal would emerge as a second stage of the INSPIRE initiative.

${ }^{243}$ See sections 3.1 and 3.4, ante.

244 See section 3.1 ante.

245 See notes 77-78, ante.

246 This was the theme of the 2005 Ministerial eGovernment Conference, Transforming Public Services, that took place under the UK Presidency of the EU 2005 in Manchester on 23-25 November 2005. See the conference proceedings at: www.egov2005conference.gov.uk/proceedings/index.asp. One speaker declared: "I'm bored with eGovernment. There is so much bad eGovernment around and it has made things worse. If we don't learn the lessons we will carry our mistakes into the transformation era”.
} 
It is submitted that this is the stage that the UK authorities have reached in their assimilation of GI and SDI for government. At a time when the Government wants to build the tools and define the regulation to make better use of all its information resources, it must now assess the merits of investing in and developing the means to exploit spatial resources as a sub-set of its broader information portfolio. Such a resource, backed by creation of the infrastructure to support it, offers government the potential for improved delivery of national and local public services, new insights into the process of developing public policy and, through its dissemination to the private sector, a boost to the economy right down to local level. ${ }^{247}$

Given such multi-dimensional possibilities, the Government now needs to look carefully at how its arrangements for developing and exploiting GI resources are being handled. ${ }^{248}$ This will involve a number of tasks including analysis, within departments, of where deployment of GI tools might be useful, as well as the taking of inventories of data resources so as to expose potential sources of GI that may not already have been identified. An infrastructure must then be developed and maintained to enable these resources to be shared. Choices as to the types of partnership to build around these activities will need to be made, together with the funding and pricing decisions that go with this. Attention must also focus on regional policy, such as that of the EU, to ensure that the UK contributes to the international regulatory debate and can access similar GIIPS resources elsewhere. The implications for GI of other requirements such as data protection and freedom of information concerns must also be taken on board.

It is the submission of this paper that the best way forward is to appoint an independent advisory forum of some kind. Ideally its remit would be to observe GI developments across the whole of government with power to make recommendations unfettered by political pressures. Facilitating such a forum would enable the Government to make more informed decisions for development of GI resources, based on the feedback it receives. As a result, a much clearer picture of what is happening across government is likely to emerge than might otherwise have been achieved if reporting responsibility was to reside within a single department or consortium of departmental interests.

The concept of an independent advisory group has worked well in the reform of Crown copyright, following the formation of the Advisory Panel on Crown Copyright. This was an independent forum of experts drawn from the Government, private sector and academic fields, created to give impartial advice to Ministers on the discharge of its Crown copyright policies. In April 2003, the Panel was renamed the Advisory Panel on Public Sector Information (APPSI). This change of title was, in part, testimony to the Panel's achievements. It had persuaded the Government that the links and disparities between Crown copyright policies and other policies, such as those for eGovernment, needed to be better understood. Moreover, it supported the Government in recognising that Crown copyright had now become a component of a broader information policy agenda and needed to be treated as such. Its remit "to open up opportunities for greater re-use of government information by private and voluntary sectors of the economy" and to advise Ministers "about changes and opportunities in the information industry", ${ }^{249}$ has enabled APPSI to offer a strategic view to Ministers as to the way in which the Government's information policies are working. It is not something that OPSI has recognised that it can undertake alone. The original preoccupation with the revenue stream from Crown copyright licensing has now given way to an

\footnotetext{
247 See notes 73 and 74 , ante.

${ }^{248} \mathrm{GI}$ is an infrastructure issue and is therefore not a vote winner with politicians - hence it takes a 'back seat' when the priorities are being set.

${ }^{249}$ Advisory Panel on Public Sector Information releases first annual report, (Cabinet Office Press Release CAB039/04, 27 July 2004).
} 
appreciation of the greater economic reward in encouraging PSI re-use. Speculating as to the potential contribution of GI within current information policy, it was strangely left to APPSI to remind observers of the claims asserted by OS as to the support its GI resources continued to make in underpinning the national economy. ${ }^{250}$ In its first Annual Report, ${ }^{251}$ APPSI wondered, anecdotally, whether the extent of such reliance was properly understood! ${ }^{252}$

APPSI continues to be successful in drawing the Government's attention to the consequences of its re-use policy operating within departments, and to the continued benefit of impartial and independent oversight. It is submitted that such a forum, working to a similar formula, could now offer timely support to the Government as it wrestles with the formation and management of its policy for GI. Such a move would go a long way towards providing the oversight, across the whole of government that must be secured if GI resources and a successful SDI are to be established here. Perhaps the recent appointment of the GI Panel by the ODPM is evidence that the Government has begun to set such a process in motion. If so, then it might be about to travel in the right direction as it confronts the task that lies ahead.

\footnotetext{
${ }^{250}$ Op. cit., note 79, ante.

${ }^{251}$ Advisory Panel on Public Sector Information $1^{\text {st }}$ Annual Report, (APPSI, July 2004).

${ }^{252}$ It suggested that as far back as 1996, between $12 \%-20 \%$ of the UK economy for goods and services was underpinned by geographical information provided by OS. This involved sums between $£ 79$ and $£ 136$ billion.
} 


\begin{tabular}{|c|c|}
\hline \multicolumn{2}{|c|}{ ACRONYMS used in this paper } \\
\hline AGI & The Association for Geographic Information \\
\hline APPSI & Advisory Panel on Public Sector Information \\
\hline DNF & The Digital National Framework \\
\hline EDT & The eGU eDelivery Team \\
\hline eGIF & eGovernment Interoperability Framework \\
\hline eGMS & eGovernment Metadata Standard \\
\hline GPS & Global Positioning System \\
\hline eGU & eGovernment Unit \\
\hline ePIMS & Electronic Property Information Mapping Service \\
\hline ESDI & European Spatial Data Infrastructure \\
\hline GEMINI & Geo-spatial Metadata Interoperability Initiative \\
\hline GI & Geographic Information \\
\hline GIS & Geographic Information Systems \\
\hline GIIPS & Geographic Information, Infrastructure, Products and Services \\
\hline GINIE & Geographic Information Network in Europe \\
\hline GI Panel & The Advisory Panel on Geographic Information \\
\hline GSi & Government Secure Intranet \\
\hline IAR & Information Asset Register \\
\hline IDeA & Improvement and Development Agency \\
\hline IGGI & Intra-Governmental Group on Geographic Information \\
\hline INSPIRE & Infrastructure for Spatial Information in Europe \\
\hline IPRs & Intellectual Property Rights \\
\hline HMSO & Her Majesty’s Stationery Office \\
\hline LeGSB & National Local e-Government Standards Body \\
\hline LLPG & Local Land and Property Gazetteer \\
\hline MSA & Mapping Services Agreement \\
\hline NCC & National Computing Centre \\
\hline NGDF & National Geospatial Data Framework \\
\hline NGO & Non-Governmental Organisation \\
\hline NLPG & National Land and Property Gazetteer \\
\hline NIMSA & National Interest Mapping Services Agreement \\
\hline NRG & NIMSA Review Group \\
\hline NSAI & National Spatial Address Infrastructure \\
\hline NSDI & United States National Spatial Data Infrastructure \\
\hline NTD & National Topographic Database \\
\hline ODPM & Office of the Deputy Prime Minister \\
\hline OGC & Open Geospatial Consortium \\
\hline OGc & Office of Government Commerce \\
\hline ONS & Office for National Statistics \\
\hline OPSI & Office of Public Sector Information \\
\hline OS & Ordnance Survey \\
\hline PAI & OS Positional Accuracy Improvement Programme \\
\hline PAF & PostCode Address File \\
\hline PGA & Pan Government Agreement \\
\hline PSI & Public Sector Information \\
\hline SDI & Spatial Data Infrastructure \\
\hline SINES & Spatial Information Enquiry Service \\
\hline SME & Small and Medium Sized Enterprises \\
\hline TOID & Topographic Identifier \\
\hline
\end{tabular}


Final 06022006 